\title{
Mitochondrial Proteome Changes Correlating with $\beta$-Amyloid Accumulation
}

\author{
Katalin Völgyi ${ }^{1,2}$ • Krisztina Háden ${ }^{2}$ - Viktor Kis ${ }^{3}$ • Péter Gulyássy ${ }^{2,4} \cdot$ Kata Badics $^{2}$. \\ Balázs András Györffy ${ }^{2,5}$ • Attila Simor ${ }^{2}$ - Zoltán Szabó ${ }^{6}$ • Tamás Janáky ${ }^{6}$. \\ László Drahos $^{4}$ • Árpád Dobolyi ${ }^{1}$ • Botond Penke ${ }^{6}$ - Gábor Juhász ${ }^{2,4}$. \\ Katalin Adrienna Kékesi ${ }^{2,7}$
}

Received: 19 July 2015 / Accepted: 23 December 2015

(C) Springer Science+Business Media New York 2016

\begin{abstract}
Alzheimer's disease (AD) is a multifactorial disease of wide clinical heterogenity. Overproduction of amyloid precursor protein (APP) and accumulation of $\beta$-amyloid $(\mathrm{A} \beta)$ and tau proteins are important hallmarks of $\mathrm{AD}$. The identification of early pathomechanisms of AD is critically important for discovery of early diagnosis markers. Decreased brain metabolism is one of the earliest clinical symptoms of $\mathrm{AD}$ that indicate mitochondrial dysfunction in the brain. We performed the first comprehensive study integrating synaptic and non-synaptic mitochondrial proteome analysis (two-dimensional differential gel electrophoresis (2D-DIGE) and mass spectrometry) in correlation with $\mathrm{A} \beta$ progression in APP/PS1 mice (3, 6, and 9 months of age). We identified changes of 60 mitochondrial proteins that reflect the progressive effect of APP overproduction and A $\beta$ accumulation on mitochondrial processes. Most of the significant-
\end{abstract}

Electronic supplementary material The online version of this article (doi:10.1007/s12035-015-9682-4) contains supplementary material, which is available to authorized users.

Katalin Völgyi

katvolgyi@gmail.com

1 MTA-ELTE NAP B Laboratory of Molecular and Systems Neurobiology, Hungarian Academy of Sciences and Eötvös Loránd University, Budapest, Hungary

2 Laboratory of Proteomics, Eötvös Loránd University, Budapest, Hungary

3 Department of Anatomy, Cell and Developmental Biology, Eötvös Loránd University, Budapest, Hungary ly affected proteins play role in the mitochondrial electron transport chain, citric acid cycle, oxidative stress, or apoptosis. Altered expression levels of Htra2 and Ethe1, which showed parallel changes in different age groups, were confirmed also by Western blot. The common regulator bioinformatical analysis suggests the regulatory role of tumor necrosis factor (TNF) in A $\beta$-mediated mitochondrial protein changes. Our results are in accordance with the previous postmortem human brain proteomic studies in $\mathrm{AD}$ in the case of many proteins. Our results could open a new path of research aiming early mitochondrial molecular mechanisms of $\mathrm{A} \beta$ accumulation as a prodromal stage of human $\mathrm{AD}$.

Keywords Alzheimer's disease $(\mathrm{AD}) \cdot \beta$-Amyloid $(\mathrm{A} \beta)$. APP/PS1 mouse model · Synaptic mitochondria · Non-synaptic mitochondria
4 MTA-TTK NAP B MS Neuroproteomics Research Group, Research Center for Natural Sciences, Hungarian Academy of Sciences, Budapest, Hungary

5 MTA-ELTE NAP B Neuroimmunology Research Group, Hungarian Academy of Sciences and Eötvös Loránd University, Budapest, Hungary

6 Medical Chemistry Department, University of Szeged, Szeged, Hungary

7 Department of Physiology and Neurobiology, Eötvös Loránd University, Budapest, Hungary 


$\begin{array}{ll}\text { Abbreviations } \\ \text { sMito } & \text { Synaptic mitochondria } \\ \text { nsMito } & \text { Non-synaptic mitochondria } \\ \text { A } \beta & \text { Amyloid- } \beta \\ \text { 2D-DIGE } & \text { Two-dimensional differential gel electrophoresis } \\ \text { WB } & \text { Western blot } \\ \text { Htra2 } & \text { Serine protease HTRA2 } \\ \text { Ethe1 } & \text { Persulfide dioxygenase ETHE1 } \\ \text { APP } & \text { Amyloid precursor protein } \\ \text { PS1 } & \text { Presenilin-1 }\end{array}$

\section{Introduction}

Neurodegenerative disorders such as Alzheimer's, Parkinson's, Huntington's disease (AD, PD, HD), and prion diseases show several high importance similarities, including neuronal loss and aggregation of disease-specific misfolded proteins in the brain. These disorders belong to the family of "protein conformational" diseases [1]. Overlapping of the misfolded proteins is typical in neurodegenerative diseases: multiple toxic proteins are accumulated in $\mathrm{AD}$ and other age-related disorders [2]. Formation and accumulation of misfolded proteins demonstrate that failure in ATP production, protein folding, and quality control may play an important role in the pathological processes [3]. Precipitation of two main proteins ( $\beta$-amyloid/A $\beta$ and hyperphosphorylated tau) is typical in $A D$ brain.

There are two main forms of AD: the early onset/familial and the late onset/sporadic form. Familial AD is caused by mutations of the amyloid precursor protein (APP) and the $\gamma$-secretase complex (presenilin-1 and presenilin-2/PS1 and 2) [4]. On the basis of clinical presentation, there are several further subtypes of $\mathrm{AD}$ (amnestic, pure amnestic, language, visuoperceptive, and executive variants) [5]. All subtypes of $\mathrm{AD}$ share common pathological hallmarks like the presence of amyloid plaques and neurofibrillary tangles. Consequently, amyloidogenic APP processing and tau hyperphosphorylation must be key events in the progress of $\mathrm{AD}$.

Formation of amyloid plaques in the brain is also a frequent hallmark of aging without dementia [6]. It has been more and more accepted that $A \beta$ accumulation itself is not necessarily the initial step of AD [7], only a consequence of preceding molecular events. However, $A \beta$ accumulation is still an important issue in $\mathrm{AD}$ progression, because intracellular $A \beta$ has toxic effects in synaptic transmission and memory trace formation as well as decreases the number of synapses [8].

The early $A \beta$ accumulation-induced molecular mechanisms cannot be studied in humans due to ethical problems of brain biopsy, and thus, animal models should be used. One of the best models is the double transgenic
APP/PS1 mouse, expressing both the human Swedish-mutant APP and a mutant PS1 [9, 10]. Cleavage of APP by $\beta$ - and $\gamma$-secretase generates both $\mathrm{A} \beta$ and APP intracellular domain (AICD) peptides [11]; therefore, beside $A \beta$ accumulation, AICD peptide level also increases in APP/PS1 mice. These animals reproduce a common process in most variants of AD. APP/PS1 mice also reproduce some symptoms of $\mathrm{AD}$, such as the age-dependent synaptic dysfunction and memory loss $[9$, 12] as well as metabolic changes due to mitochondrial dysfunction $[6,8,10]$, which are characteristic for human $\mathrm{AD}$ as well.

It has been revealed that overproduced APP and $A \beta$ are present in the mitochondria of APP transgenic mouse models and human AD brain [13-15]. The presence of mitochondrial $\mathrm{A} \beta$ correlates well with mitochondrial dysfunction in the synapses [16] because synaptic mitochondria are particularly sensitive to $A \beta$ [17]. $A \beta$ is present in the synaptic mitochondria of APP/PS1 transgenic mice at early stage, when no accumulation of extracellular $A \beta$ can be detected [17].

Mitochondrial failure and dysfunction are an early sign of $\mathrm{AD}$ and other neurodegenerative disorders $[10$, 18-20]. Brain hypometabolism and progressive decrease of brain metabolism are the earliest clinical symptoms of AD [1]. Selection of high-risk potential AD groups of aging humans, before manifestation of cognitive impairment, represents an important aim of AD research. Changes in the level of individual mitochondrial proteins could serve as early metabolic markers for AD. Because of limitations of human studies, a necessary compromise could be the use of the double transgenic APP/PS1 mouse as a proper model for studying early molecular mechanisms of AD.

Mitochondrial proteome changes in AD models [21-24] and the postmortem brain human proteomics data of AD [25-29] confirm the possibility of early mitochondrial protein markers for AD. However, the already published mitochondrial proteomics data are incoherent because of using different animal models and different time points of investigation in $\mathrm{AD}$ development. Therefore, a coherent, comprehensive study of synaptic and non-synaptic mitochondrial proteome of animal model of $\mathrm{AD}$ is needed to reveal early molecular mechanisms of AD. Our aim was to conduct a systematic study of proteome changes in synaptic (sMito) and non-synaptic mitochondria (nsMito) of APP/PS1 mice at different ages.

The present study focuses on two major questions: (i) Are there $A \beta$-induced mitochondrial proteome changes as early as 3 months of age in APP/PS1 mice without behavioral changes? (ii) How do the synaptic and/or non-synaptic mitochondrial proteomes change in the time frame of 3 to 9 months of age? 


\section{Methods}

\section{Animal Model}

The APP/PS1 mice carry the Mo/Hu APP695swe (695-amino acid isoform of human APP) and PS1-dE9 (mutant human PS1) mutations. PS1-dE9 alters the specificity of $\gamma$-secretase to favor production of $A \beta_{42}$ and consequently shifts the ratio of $A \beta_{40} / A \beta_{42}$. Experiments begun with 3-month-old animals without amyloid deposits and behavioral changes. $A \beta$ deposits appear at 6 months of age mostly in the cerebral cortex, while the amyloid plaques are abundant in the hippocampus and cerebral cortex at 9 months of age [30]. Performance of APP/PS1 mice in the Morris water maze gradually declines between 3 and 12 months of age [31]. Therefore, we selected 3-, 6-, and 9-month-old APP/PS1 and C57BL/6 (B6) control mice for proteomics $(n=36)$ and light microscopy experiments $(n=12)$. Handling and experimentation on animals were performed in conform to Council Directive 86/609/ EEC, the Hungarian Act of Animal Care, and the Experimentation (1998, XXVIII) and local regulations for care and use animals for research.

\section{$\beta$-Amyloid Progression Detection in 3-, 6-, and 9-Month-Old APP/PS1 Mice Brain}

All reagents used for microscopy were obtained from Sigma-Aldrich. Twelve mice were used for microscopic investigations (two mice per group). Brains were transcardially perfused with saline then with $4 \%$ formaldehyde, $0.05 \%$ glutaraldehyde, and $0.2 \%$ saturated picric acid in $0.1 \mathrm{M}$ phosphate buffer $(\mathrm{pH}=7.4 ; \mathrm{PB})$ for $25 \mathrm{~min}$. The brains were left in the skull overnight. Blocks containing the dorsal hippocampus were sectioned at $50 \mu \mathrm{m}$ with a vibratome VT $1000 \mathrm{~S}$ (Leica) and stored in $0.1 \mathrm{M}$ PB supplemented with $0.05 \%$ sodium azide. Sections were washed with $0.1 \mathrm{M} \mathrm{Na}$-cacodylate and postfixed in reduced osmium $(0.5 \%$ osmium tetroxide, $0.75 \%$ potassium hexacyano-ferrate in $0.1 \mathrm{M}$ Na-cacodylate) for $60 \mathrm{~min}$, en bloc stained with half-saturated aqueous uranyl acetate, dehydrated, and flat embedded on slides in Durcupan resin (Fluka). Sections were photographed with a Zeiss Axio Imager Z1 microscope (Zeiss) equipped with a Cc1 camera.

For electron microscopy, the coverslips were removed, and small pieces from the somatosensory cortex and dorsal hippocampus were re-embedded. Ultrathin sections $(70 \mathrm{~nm})$ were collected on 300-mesh copper grids and stained with uranyl acetate for $5 \mathrm{~min}$ and lead citrate for $30 \mathrm{~s}$. Grids were examined in JEOL JEM 1011 electron microscope (JEOL) operating at $60 \mathrm{kV}$. Images were taken with an Olympus Morada 11-MP camera (Olympus) and iTEM software (Olympus).

\section{Isolation of Synaptic and Non-synaptic Mitochondria}

Metabolically active sMito and nsMito were isolated according to our already published protocol [32]. Briefly, mice were decapitated and the brains rapidly removed, washed in artificial cerebrospinal fluid (ACSF), and immediately cooled in dry ice. Brain tissue (weighing $200 \mathrm{mg}$ per animal) was homogenized in $700 \mu \mathrm{L}$ of ice-cold isolation buffer $(225 \mathrm{mM}$ mannitol, $75 \mathrm{mM}$ sucrose, $20 \mathrm{mM}$ HEPES-KOH, $1 \mathrm{mM}$ EGTA, protease and phosphatase inhibitor cocktails, $\mathrm{pH}$ adjusted to 7.2 with $\mathrm{KOH}$ ) using pre-chilled Dounce homogenizer (Kontes Glass Co.; eight-stroke large clearance + eight-stroke small clearance). All steps were performed at $4{ }^{\circ} \mathrm{C}$ or on ice with ice-cold buffers and solutions. The resultant homogenates were centrifuged at $1300 \mathrm{~g}$ for $5 \mathrm{~min}$. Supernatants were collected, and an equal volume of $30 \%$ Percoll in isolation buffer was added. The resultant homogenate was layered with $1-\mathrm{mL}$ syringe (Tuberculin, $0.5 \times 25-\mathrm{mm}$ needle) on a discontinuous Percoll gradient (with the bottom layer containing $40 \%$, followed by a $24 \%$, and, finally, the sample in $15 \%$ Percoll solution) and centrifuged at $34,000 \mathrm{~g}$ for $8 \mathrm{~min}$. After centrifugation, band 2 (the interface between 15 and $23 \%$ containing synaptosome) and band 3 (the interface between 23 and $40 \%$ containing nsMito) were collected from the density gradient, using a tight bore medical needle (26 gauge) and a $2-\mathrm{mL}$ syringe. The samples were transferred to another centrifuge tube by manually pushing through again in the same tight bore needle with high speed. As the synaptosomal fraction was getting through the needle, it became fractured by the sheer force and the internal synaptic mitochondria were released. The samples were diluted with four volumes of isolation buffer and centrifuged at $34,000 \mathrm{~g}$ for $8 \mathrm{~min}$. The resultant loose pellets containing exclusively the sMito or nsMito were collected and washed at $8000 \mathrm{~g}$ for $15 \mathrm{~min}$. The final sMito and nsMito pellets were precipitated overnight in ice-cold acetone. The electron microscopic and fluorescence-activated cell sorting (FACS) validation of sMito and nsMito samples have already been published [32].

\section{Proteomic Analysis by 2D-DIGE}

The detailed two-dimensional differential gel electrophoresis (2D-DIGE) protocol has been described in our earlier studies $[32,33]$. We used 2D-DIGE Saturation Labeling method. Equipment and software were supplied from GE Healthcare, Little Chalfont, UK. Briefly, acetone-precipitated mitochondrial samples were resuspended in a lysis buffer containing $7 \mathrm{M}$ urea, $2 \mathrm{M}$ thiourea, $4 \%$ CHAPS, $20 \mathrm{mM}$ Tris, and $5 \mathrm{mM}$ magnesium-acetate. The $\mathrm{pH}$ was adjusted to 8.0 , and the protein concentrations were determined by $2 \mathrm{D}$-Quant Kit. Samples of $5 \mu \mathrm{g}$ were labeled by using CyDye DIGE Fluor Saturation Labeling Kit according to the manufacturer's instructions. The sMito and nsMito samples were labeled with 
Cy5, and the internal standard (pool of equal amounts of all samples within the experiment) was labeled with $\mathrm{Cy} 3$. The two differently labeled protein samples were merged, and 12 mixtures (six-six gels simultaneously) were run. Isoelectric focusing was performed on 24-cm immobilized $\mathrm{pH}$ gradient (IPG) strips ( $\mathrm{pH} 3-10 \mathrm{NL}$ ) for $24 \mathrm{~h}$ in an Ettan IPGphor instrument, to attain a total of $80 \mathrm{kVh}$. The applied voltages were as follows: $30 \mathrm{~V}$ for 3 -h step, $500 \mathrm{~V}$ for $5 \mathrm{~h}$ gradient, $1000 \mathrm{~V}$ for $6 \mathrm{~h}$ gradient, $8000 \mathrm{~V}$ for $3 \mathrm{~h}$ gradient, and $8000 \mathrm{~V}$ for 6 -h step mode. Focused proteins were reduced in equilibrating buffer containing $6 \mathrm{M}$ urea, $50 \mathrm{mM}$ Tris ( $\mathrm{pH} 8.8$ ), $30 \%(v / v)$ glycerine, $2 \%(w / v)$ sodium dodecyl sulfate (SDS), Bromophenol Blue (trace), and $1 \%(w / v)$ mercaptoethanol for $20 \mathrm{~min}$. Subsequently, the IPG strips were loaded onto $10 \%$ polyacrylamide gels $(24 \times 20 \mathrm{~cm})$, and SDS-PAGE was performed using an Ettan DALT Six System. Gels were scanned in a Typhoon TRIO+ scanner selecting appropriate lasers and filters. Gel images were visualized by ImageQuant TL software.

Differential protein analysis was performed using DeCyderTM 2D software 7.0 Differential In-gel Analysis (DIA) and Biological Variance Analysis (BVA) modules. The internal standard sample was the same in all gels, and fluorescent intensity changes of protein spots were normalized to the values of the corresponding internal standard. It provided an image, against which, all other gel images were normalized. Independent Student's $t$ test was performed to determine the statistical significance of the protein abundance changes for each protein spot.

\section{Preparative 2D Gel Electrophoresis for Protein Identification}

For the identification of proteins in spots of interest, preparative 2D gel electrophoresis was performed, separately, using a total of $800 \mu \mathrm{g}$ of proteins per gel. Resolved protein spots were visualized by Colloidal Coomassie Blue G-250 (Merck, Darmstadt, Germany).

\section{Protein Identification by Mass Spectrometry (nanoUHPLC-MS/MS)}

Digested protein samples were analyzed on a Waters nanoACQUITY UPLC system coupled with a Micromass Q-TOF premier mass spectrometer. The samples (5- $\mu \mathrm{L}$ full-loop injection) were initially transferred with an A eluent to the pre-column at a flow rate of $10 \mu \mathrm{L} / \mathrm{min}$ for $1 \mathrm{~min}$. Mobile phase A was $0.1 \%$ formic acid in water whilst mobile phase B was $0.1 \%$ formic acid in acetonitrile with $350 \mathrm{~nL} / \mathrm{min}$ flow rate which were applied on a Waters BEH130 C-18 $75 \mu \mathrm{m} \times 250 \mathrm{~mm}$ column with $1.7-\mu \mathrm{m}$ particle size $\mathrm{C}-18$ packing. The linear gradient was as follows: 3-10\% $\mathrm{B}$ over 0-1 min, 10-
$30 \%$ B over 1-20 min, and 30-100\% B over 20 $21 \mathrm{~min}$, and the composition was maintained $100 \% \mathrm{~B}$ for $1 \mathrm{~min}$ and then returned to $3 \%$ during $1 \mathrm{~min}$. The column was re-equilibrated at initial conditions for 22 min. The column was maintained at $45^{\circ} \mathrm{C}$. The mass spectrometer operated in DDA mode with lock mass correction, with a nominal mass accuracy of $3 \mathrm{ppm}$. The instrument was operated in positive ion mode, performing full-scan analysis over the $m / z$ range $400-1990$ at $1 / 1$ spectra/s for mass spectrometry (MS) and 50-1990 in MS/ MS. The source temperature was set at $85^{\circ} \mathrm{C}$, and nitrogen was used as the desolving gas ( 0.5 bar). Capillary voltage and cone voltage were maintained at $3.3 \mathrm{kV}$ and $26 \mathrm{~V}$, respectively.

Data were processed by the WATERS ProteinLynx Global Server 2.4 software using default settings. Database search was performed by Mascot 2.2 (Matrix Science, London, UK) which was set up to search Swissprot database adjusted to tryptic digestion. Data were searched with 0.15 -Da fragment and 30-ppm parent ion mass tolerances. Oxidation of methionine was specified as a variable modification.

Scaffold software (version Scaffold 3.62, Proteome Software Inc., Portland, OR) was used to validate MS/ MS-based peptide and protein detection. Protein identifications were accepted if the probability was higher than $95.0 \%$ and contained at least two identified peptides. Protein probabilities were assigned by the Protein Prophet algorithm.

\section{Functional Clustering}

Significantly altered proteins were clustered on the basis of the UniProt (http://www.uniprot.org/) and Gene Ontology (http:// geneontology.org/) databases. The proteins were clustered in groups according to their most relevant cellular functions, and roles in human AD pathology were also listed.

\section{Bioinformatical Analysis of Mitochondrial Protein Changes}

We analyzed the interactions between significantly changed mitochondrial proteins with Ariadne Genomics Pathway Studio $^{\circledR} 9.0$ software environment (ResNet 9.0, 2010Q4, Ariadne Genomics, Inc, Rockville, MD, USA) [34].

Common regulator and common target analysis were made for all mitochondrial protein changes (altogether sMito and nsMito at 3, 6, and 9 months of age). We selected for further analysis common regulator and target proteins, having minimum seven relationships with significantly changed mitochondrial proteins from our experimental results. 


\section{Htra2 and Ethe1 Protein Validation by WB}

The highest fold differences in the altered synaptic mitochondrial proteins that showed significant protein-level changes in all three age groups were Htra2 and Ethe1; thus, we selected them for validation by Western blot. We used the same synaptic mitochondrial samples as utilized in the 2D-DIGE method. Proteins were separated by Tricine-SDS-polyacrylamide gel electrophoresis on $15 \%$ polyacrylamide gels then transferred to HybondTM-LFP PVDF transfer membranes (GE Healthcare). The membranes were blocked with $5 \%$ BSA in Tris-buffered saline and $0.1 \%$ Tween 20 (TBS-T) and then washed in TBS-T. The blots were incubated with the following primary antibodies: rabbit anti-Htra2 polyclonal antibody (15775-1-AP, Proteintech) at 1:1000 and rabbit anti-Ethe1 polyclonal antibody (ab154041; Abcam) at 1:500 dilution. Subsequently, the membranes were washed $4 \times 5 \mathrm{~min}$ in TBS-T followed by the incubation with ECL Plex CyDye-conjugated anti-rabbit IgG secondary antibody (GE Healthcare). After washing steps in TBS-T and then in TBS, the bands were visualized using a Typhoon TRIO+ scanner. Fluorescent intensities were quantified using the ImageQuant TL software. Differences between APP/PS1 and B6 samples were statistically analyzed using Student's $t$ test. Differences between 3-, 6-, and 9-month-old age groups were statistically analyzed using one-way ANOVA Tukey post hoc analysis.

\section{Results}

\section{Distribution of $A \beta$ Plaques}

Our studies confirmed that 3-month-old APP/PS1 mice do not develop amyloid deposits (Fig. 1e). The amyloid plaques appear at 6 months of age in transgenic animals (Fig. 1f), while hippocampus and cerebral cortex show high amyloid burdens (Fig. 1g) at 9 months of age. Mice from line B6 (controls) show no amyloid deposition throughout the aging (Fig. 1a-c). The timing of $A \beta$ plaque formation reproduced data known from previous studies [30, 31]. We found amyloid plaques both at light (Fig. 1d) and at electron microscopy levels (Fig. 1h).

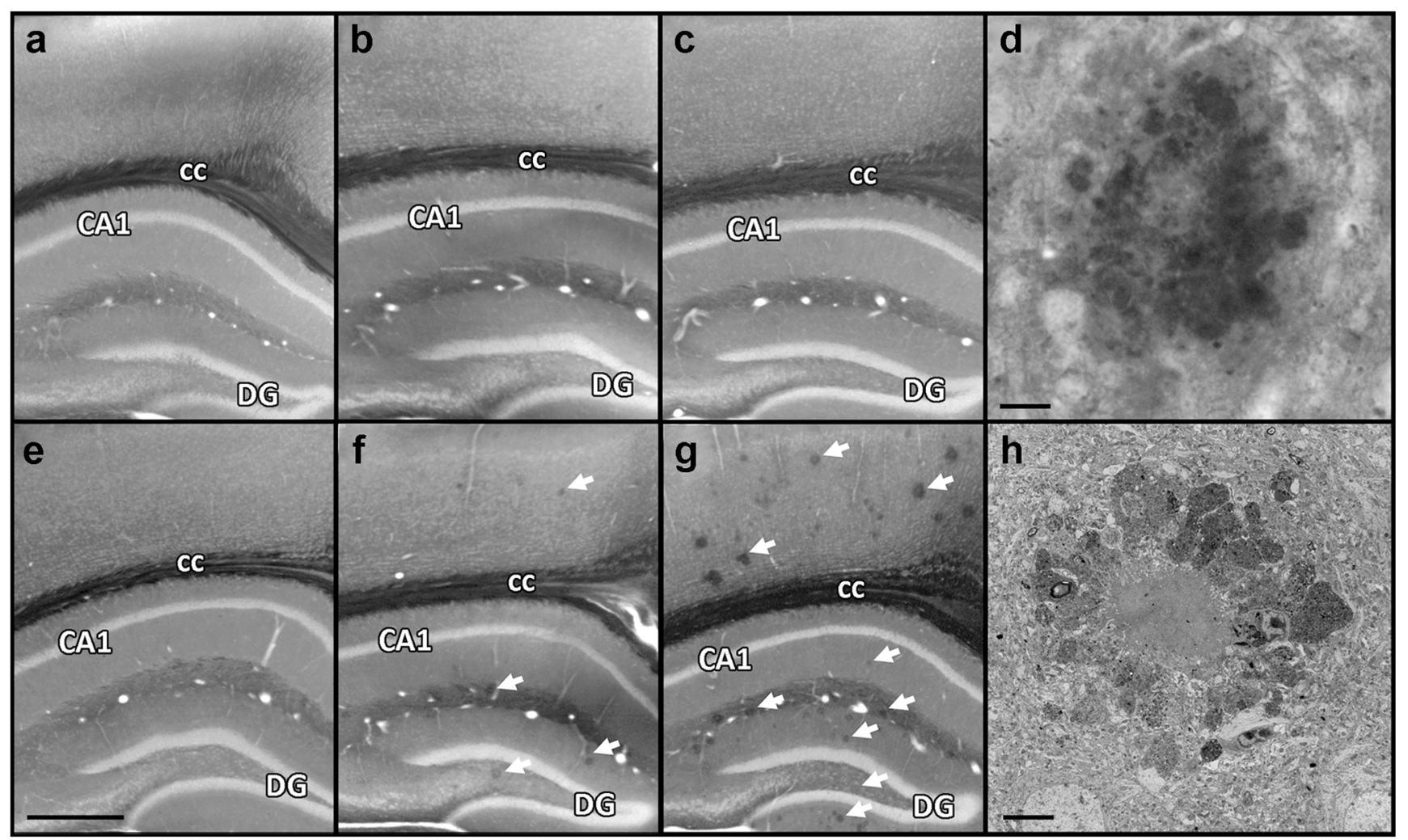

Fig. 1 Representative light microscopy images of 3-, 6-, and 9-monthold B6 control (a-c) and APP/PS1 transgenic mice (e-g) hippocampal and cortical brain regions. White arrows indicate amyloid plaque that appears in 6- and spread in 9-month-old APP/PS1 mice brain. Higher- magnification image of an amyloid plaque stained with reduced osmium (d). Low-power electron micrograph of the same amyloid plaque as shown in d (h). Scale bars: $\mathbf{a}-\mathbf{g} 500 \mu \mathrm{m}, \mathbf{d}, \mathbf{h} 20 \mu \mathrm{m}$ (CA1 cornu ammonis $1, D G$ dentate gyrus, $c c$ corpus callosum) 


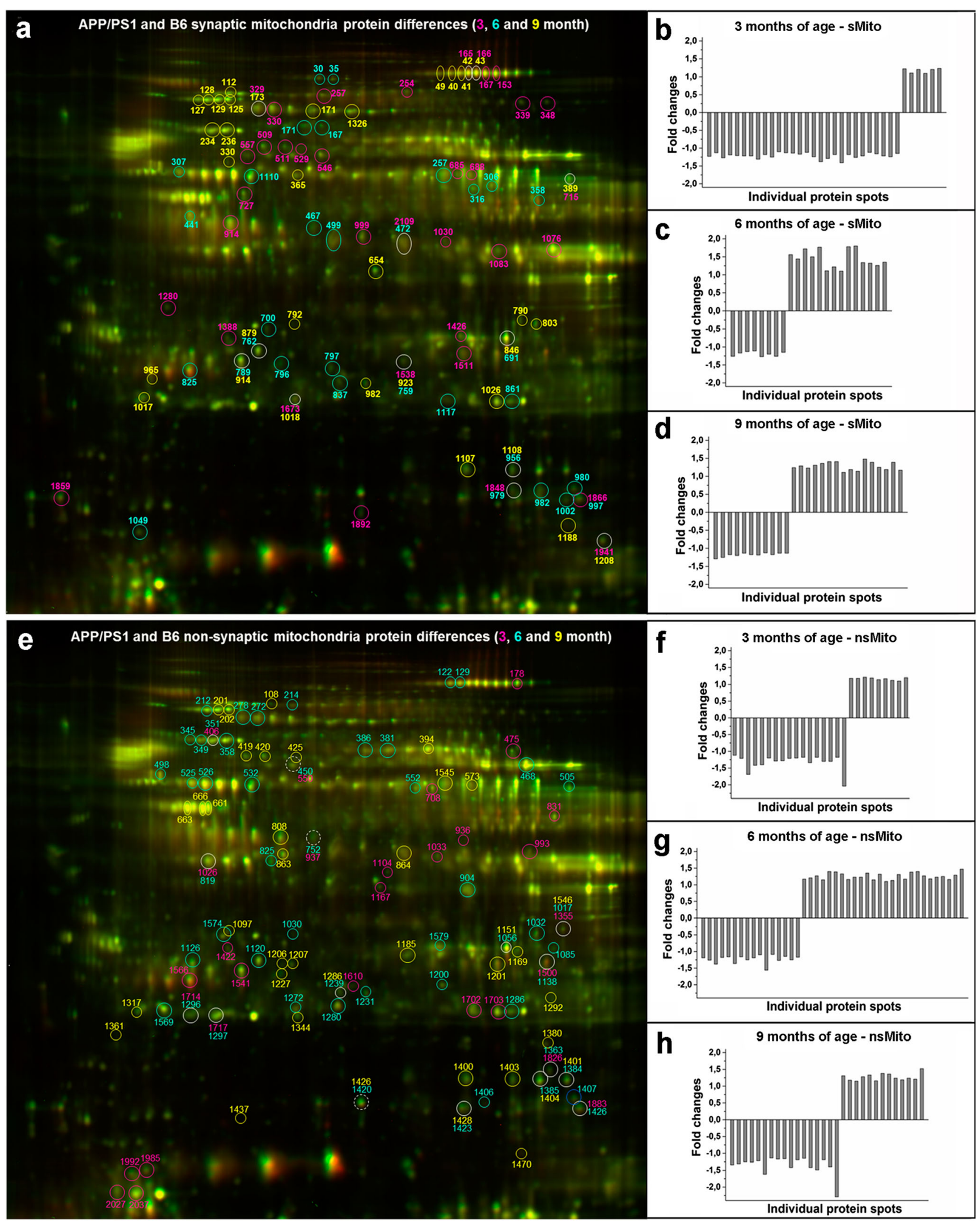


Fig. 2 Representative 2D-DIGE image with labeled locations of synaptic mitochondrial significant protein changes on the gel (a). Fold changes of the synaptic mitochondrial proteins of 3 (b)-, 6 (c)-, and 9month-old animals (d). Representative 2D-DIGE image with labeled locations of non-synaptic mitochondrial significant protein changes on the gel (e). Fold changes of the non-synaptic mitochondrial proteins of 3-(f), 6-(g), and 9-month-old animals (h). All identified protein spots are circled. Pink, turquoise, and yellow circles indicate significant protein spot changes of 3-, 6-, and 9-month-old animals, respectively. The spot numbers above the circles refer to the major genes identified in the particular spot and described in Table 1

\section{Proteomic Examination by Two-Dimensional Differential Gel Electrophoresis}

\section{D-DIGE Spot Changes and Protein Identification by nanoUHPLC-MS/MS}

We detected approximately 1200 quantitatively measurable spots per gel with 2D-DIGE (full stain labeling) in sMito and nsMito fractions from brain tissues of 3-, 6-, and 9-month-old APP/PS1 mice (altogether $6 \times 12$ gels). Forty-three different nsMito proteins (3 months nsMito: 21; 6 months nsMito: 30; 9 months nsMito: 25 ) and 42 sMito proteins (3 months sMito: 24; 6 months sMito: 19; 9 months sMito: 19) were significantly changed in APP/PS1 mice compared to B6 mice by more than 1.1fold change (there were common proteins between different age groups). Representative 2D-DIGE gel images with differentially expressed sMito and nsMito spots are shown in Fig. 2a, e, respectively. Fold changes of fluorescence intensities between control and transgenic sMito sample spots (Fig. 2b-d) were in the range of -1.41 to 1.80 and in the range of -2.29 to 1.52 in the nsMito samples (Fig. 2f-h).

Proteins of significantly changed spots $(p<0.05$, Student's $t$ test calculated in BVA module of the DeCyderTM 2D software 7.0) were identified by LC/ MS-MS analysis. We described a total of 60 different proteins (Table 1). Several proteins were present in more than one spot suggesting posttranslational modification or the presence of protein isoforms.

\section{Functional Clustering of Mitochondrial Protein Changes}

The identified, altered proteins participate in a variety of mitochondrial processes including tricarboxylic acid (TCA) cycle $(n=11)$, electron transport chain (ETC) $(n=15)$, oxidative stress and apoptosis $(n=10)$, protein transport mechanism $(n=2)$, mitochondrial protein synthesis and folding $(n=4)$, glycolysis and gluconeogenesis $(n=2)$, nucleotide metabolism $(n=4)$, ketone body metabolism $(n=2)$, lipid metabolism $(n=2)$, amino acid metabolism $(n=2)$, lactate metabolism $(n=1)$, glutathione metabolism $(n=1)$, synaptic transmission $(n=1)$, signal transduction $(n=1)$, and others with unknown function $(n=2)$ (Table 1, Fig. 3). We also depicted the significant synaptic (Fig. 4a) and non-synaptic mitochondrial protein changes (Fig. 4b) on the basis of mitochondrial biochemical pathways in each age group.

Expressions of ETC proteins changed in the greatest extent. Two subunits of complex I, NADH dehydrogenase [ubiquinone] flavoprotein 2 (Ndufv2) (1.50-fold change) and NADH dehydrogenase [ubiquinone] iron-sulfur protein 8 (Ndufs8) (1.77-fold change), showed the highest protein-level changes in the 6 months of age sMito (Table 1). Proteins belonging to the ETC showed both increased and decreased levels in APP/PS1 model in correlation with age.

The majority of proteins belonging to the TCA cycle showed downregulation at 3-month-old age, both in sMito (Fig. 4a) and nsMito (Fig. 4b). Interestingly, at 6 months of age, most of these proteins showed increased levels, which might reflect a compensatory mechanism. In the 9-month-old late phase, TCA cycle proteins showed bidirectional changes. Among these proteins, pyruvate dehydrogenase E1 component subunit alpha somatic form (Pdha1) (1.56-fold change) and malate dehydrogenase (Mdh2) (1.72-fold change) showed the highest alterations. Expression levels of both these proteins were increased in the 6 months of age sMito, as well (Fig. 4).

Serine protease Htra2/Omi (Htra2) and persulfide dioxygenase ETHE1 (Ethe1) showed the greatest synaptic mitochondrial protein changes involved in oxidative stress response and apoptosis. These proteins showed parallel expression level changes in the different age groups $(\downarrow \uparrow \downarrow)$. These findings were also validated with Western blot (WB) (Fig. 5).

\section{Bioinformatics Analysis of Mitochondrial Protein Changes}

We found 17 different common regulator proteins. Based on the UniProt and Gene Ontology databases, the common regulators are important cytokines $(n=3)$, protein kinases $(n=3)$, transcription factors $(n=3)$, activators $(n=3)$, hormones $(n=2)$, inhibitors $(n=2)$, and a chaperone $(n=1)$ (Fig. 6a). Regulator proteins showing remarkably high number of relationships were $\mathrm{Sp} 1$ (transcription factor Sp1), insulin (INS), angiotensinogen (Agt), and tumor necrosis factor (TNF) alpha $(9,10,10$, and 14 relationships, respectively, with the altered mitochondrial proteins).

We found ten different common target proteins. Based on the UniProt and Gene Ontology databases, the 
Table 1 Protein differences between APP/PS1 and B6 mouse synaptic and non-synaptic mitochondria arranged in functional clusters

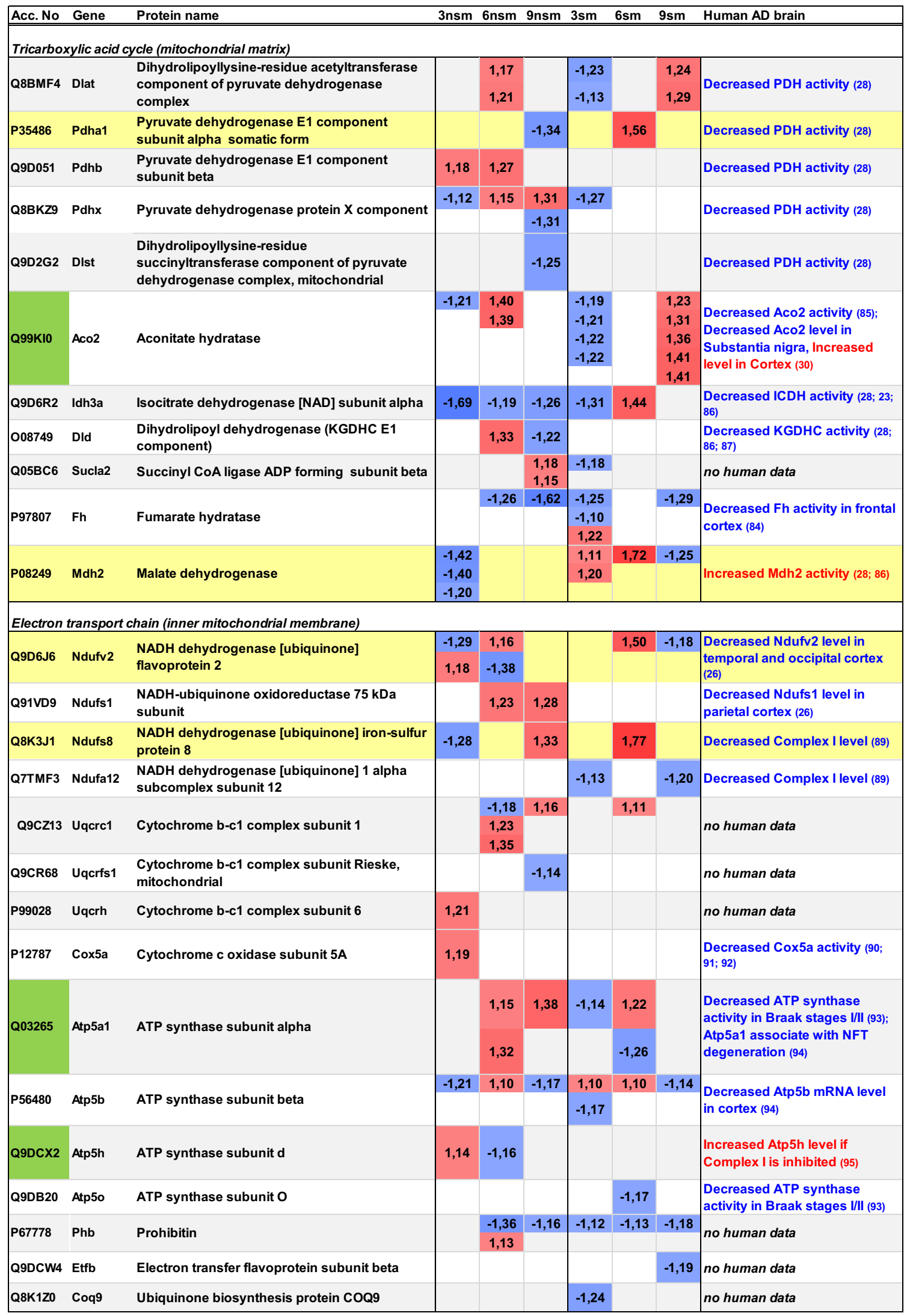


Table 1 (continued)

\begin{tabular}{|c|c|c|c|c|c|c|c|c|c|}
\hline Acc. No & Gene & Protein name & $3 \mathrm{nsm}$ & $6 \mathrm{nsm}$ & 9 nsm & $3 \mathrm{sm}$ & 6sm & 9sm & Human AD brain \\
\hline \multicolumn{10}{|c|}{ Oxidative stress and apoptosis (mitocondrial matrix, intermembrane space, cytoplasm) } \\
\hline Q9DCM0 & Ethe1 & Persulfide dioxygenase ETHE1 & & & & $-1,38$ & 1,78 & $-1,13$ & no human data \\
\hline P08228 & Sod1 & Superoxide dismutase $[\mathrm{Cu}-\mathrm{Zn}]$ & & $-1,25$ & 1,36 & & & & $\begin{array}{l}\text { Increased plasma Sod1 level in } \\
\text { Alzheimer type dementia } \\
\text { patients (93) }\end{array}$ \\
\hline P09671 & Sod2 & Superoxide dismutase [Mn] & $\begin{array}{l}1,17 \\
1,12\end{array}$ & $-1,19$ & & & $-1,11$ & 1,11 & $\begin{array}{l}\text { Increased Sod2 level in plasma } \\
(96)\end{array}$ \\
\hline Q61171 & Prdx2 & Peroxiredoxin-2 & & & & & & 1,19 & Increased Prdx2 level (88) \\
\hline P20108 & Prdx3 & Thioredoxin-dependent peroxide reductase & 1,10 & $\begin{array}{l}1,31 \\
1,17\end{array}$ & 1,24 & $-1,29$ & & 1,14 & Decreased Prdx3 level (88; 97) \\
\hline P99029 & Prdx5 & Peroxiredoxin-5 & $\begin{array}{l}-1,20 \\
-1,18\end{array}$ & $\begin{array}{r}1,38 \\
-1,10\end{array}$ & $\begin{array}{l}1,19 \\
1,24\end{array}$ & $-1,18$ & $\begin{array}{l}-1,27 \\
-1,20\end{array}$ & & no human data \\
\hline 008709 & Prdx6 & Peroxiredoxin- 6 & & & & & & $\begin{array}{l}-1,18 \\
-1,14\end{array}$ & $\begin{array}{l}\text { Increased Prdx6 level in } \\
\text { astorctes (98) }\end{array}$ \\
\hline Q9JIY5 & Htra2 & Serine protease HTRA2 & & & & $-1,41$ & 1,80 & $-1,42$ & Increased Htra2 activity (29) \\
\hline Q60932 & Vdac1 & $\begin{array}{l}\text { Voltage-dependent anion-selective channel } \\
\text { protein } 1\end{array}$ & & $\begin{array}{r}-1,56 \\
-1,09\end{array}$ & $\begin{array}{l}1,21 \\
1,52\end{array}$ & & $\begin{array}{c}1,34 \\
-1,26\end{array}$ & & $\begin{array}{l}\text { Decreased Vdac1 level in } \\
\text { cortex (99) }\end{array}$ \\
\hline Q60930 & Vdac2 & $\begin{array}{l}\text { Voltage-dependent anion-selective channel } \\
\text { protein } 2\end{array}$ & & 1,14 & & & & & $\begin{array}{l}\text { Increased Vdac2 level in } \\
\text { temporal ctx (67) }\end{array}$ \\
\hline \multicolumn{10}{|c|}{ Protein transport mechanism (outer/inner mitochondrial membrane) } \\
\hline Q9CZW5 & Tomm70a & Mitochondrial import receptor subunit TOM70 & & & & & & 1,48 & $\begin{array}{l}\text { A } \beta \text { transport via TOM complex } \\
(100,101)\end{array}$ \\
\hline Q9D880 & Timm50 & $\begin{array}{l}\text { Mitochondrial import inner membrane } \\
\text { translocase subunit TIM50 }\end{array}$ & $-1,34$ & & & $-1,18$ & & & $\begin{array}{l}A \beta \text { transport via TIM23 } \\
(100,101)\end{array}$ \\
\hline \multicolumn{10}{|c|}{ Mitochondrial protein synthesis and folding (mitochondrial matrix) } \\
\hline P63038 & Hspd1 & $60 \mathrm{kDa}$ heat shock protein & 1,20 & $\begin{array}{l}1,40 \\
1,27 \\
1,18\end{array}$ & & & & $\begin{array}{l}1,25 \\
1,19\end{array}$ & $\begin{array}{l}\text { Increased Hspd1 level if } \\
\text { Complex I is inhibited (95) }\end{array}$ \\
\hline P38647 & Hspa9 & Stress-70 protein & & 1,23 & & & & 1,39 & Decreased mRNA level (102) \\
\hline Q8BFR5 & Tufm & Elongation factor $\mathrm{Tu}$ & $-1,18$ & 1,25 & & & & & $\begin{array}{l}\text { HNE-modified Tufm in MCI } \\
\text { brain (103) }\end{array}$ \\
\hline Q3UGW4 & Clpp & $\begin{array}{l}\text { ATP-dependent Clp protease proteolytic } \\
\text { subunit }\end{array}$ & & & $-1,19$ & & & & no human data \\
\hline \multicolumn{10}{|c|}{ Glycolysis and gluconeogenesis (mitochondrial matrix) } \\
\hline Q64521 & Gpd2 & Glycerol 3 phosphate dehydrogenase (matrix) & & & & $\begin{array}{c}-1,26 \\
1,20 \\
1,23\end{array}$ & & & no human data \\
\hline P17751 & Tpi1 & Triosephosphate isomerase & & & & $-1,22$ & & & $\begin{array}{l}\text { A } \beta \text { induce Tpi nitrotyrosination } \\
(104)\end{array}$ \\
\hline \multicolumn{10}{|c|}{ Nucleotide metabolism (mitochondrion) } \\
\hline Q9WUR9 & Ak4 & Adenylate kinase isoenzyme 4 (matrix) & & 1,16 & & $-1,12$ & & & Increased Ak level (105) \\
\hline P15532 & Nme4 & $\begin{array}{l}\text { Nucleoside diphosphate kinase } \\
\text { (intermembrane space) }\end{array}$ & & $-1,27$ & & & & & Decreased Nme4 activity (27) \\
\hline P30275 & Ckmt1 & $\begin{array}{l}\text { Creatine kinase U-type (inner mitochondrial } \\
\text { membrane) }\end{array}$ & & & & & $-1,15$ & & $\begin{array}{l}\text { Decreased Ckmt1 in Substantia } \\
\text { nigra and Cortex (30) }\end{array}$ \\
\hline Q8K4Z3 & Apoa1bp & $\begin{array}{l}\text { NAD(P)H-hydrate epimerase } \\
\text { (Apolipoprotein A-l-binding protein) }\end{array}$ & & & & $-1,16$ & & & no human data \\
\hline \multicolumn{10}{|c|}{ Ketone bodies metabolism (mitochondrial matrix) } \\
\hline Q9D0K2 & Oxct1 & $\begin{array}{l}\text { Succinyl-CoA:3-ketoacid-coenzyme A } \\
\text { transferase } 1\end{array}$ & $-1,30$ & 1,29 & & & & & Increased Oxct level (106) \\
\hline Q8QZT1 & Acat1 & Acetyl CoA acetyltransferase & & & & & 1,32 & 1,17 & no human data \\
\hline \multicolumn{10}{|c|}{ Lipid metabolism (mitochondrial matrix) } \\
\hline \multirow[b]{2}{*}{ Q8BH95 } & \multirow[b]{2}{*}{ Echs1 } & \multirow[b]{2}{*}{ Enoyl-CoA hydratase } & $-1,30$ & $-1,15$ & $-1,19$ & & & $-1,14$ & \multirow{2}{*}{ no human data } \\
\hline & & & & & $-1,15$ & & & & \\
\hline Q8BMS1 & Hadha & Trifunctional enzyme subunit alpha & & & & $-1,22$ & $\begin{array}{l}1,26 \\
1,35\end{array}$ & & Decreased Hadha level (107) \\
\hline \multicolumn{10}{|c|}{ Amino acid metabolism (mitochondrial matrix) } \\
\hline Q8QZS1 & Hibch & 3-hydroxyisobutyryl-CoA hydrolase & $-1,18$ & & & & & & no human data \\
\hline Q9CWS0 & Ddah1 & $\begin{array}{l}\mathrm{N}(\mathrm{G}), \mathrm{N}(\mathrm{G}) \text {-dimethylarginine } \\
\text { dimethylaminohydrolase } 1\end{array}$ & & $-1,25$ & & & & & $\begin{array}{l}\text { Oxidatively modified Ddah1 in } \\
\text { inherited AD brain (108) }\end{array}$ \\
\hline
\end{tabular}


Table 1 (continued)

\begin{tabular}{|c|c|c|c|c|c|c|c|c|c|}
\hline Acc. No & Gene & Protein name & 3nsm & 6nsm & 9nsm & $3 \mathrm{sm}$ & $6 \mathrm{sm}$ & $9 \mathrm{sm}$ & Human AD brain \\
\hline \multicolumn{10}{|c|}{ Lactate metabolism (mitochondrion, cytoplasm) } \\
\hline P16125 & Ldhb & L-lactate dehydrogenase B chain & & & $-1,42$ & & & & $\begin{array}{l}\text { Decreased Ldhb level in Cortex } \\
\text { and Hippocampus (30) }\end{array}$ \\
\hline \multicolumn{10}{|c|}{ Glutathione metabolism (mitochondrion, cytoplasm) } \\
\hline P19157 & Gstp1 & Glutathione S-transferase P 1 & & & $-1,49$ & & & & $\begin{array}{l}\text { Gstp1 gene polymorphism } \\
\text { influence the risk of AD (109) }\end{array}$ \\
\hline \multicolumn{10}{|c|}{ Synaptic transmission (mitochondrion, synapse) } \\
\hline 055042 & Snca & Alpha-synuclein & & & & $-1,24$ & & & $\begin{array}{l}\text { Increased Snca level in } \\
\text { amygdala, limbic areas and } \\
\text { inferior temporal gyrus (110; 111; } \\
\text { 112) }\end{array}$ \\
\hline \multicolumn{10}{|c|}{ Signal transduction (mitochondrion, synapse) } \\
\hline 055042 & Pebp1 & Phosphatidylethanolamine-binding protein 1 & & & $-2,29$ & $-1,15$ & & & $\begin{array}{l}\text { Decreased Pebp mRNA level in } \\
\text { hippocampus (65) }\end{array}$ \\
\hline \multicolumn{10}{|c|}{ Others (mitochondrion, cytoplasm) } \\
\hline D3Z0L4 & Chchd3 & $\begin{array}{l}\text { Coiled-coil-helix-coiled-coil-helix domain- } \\
\text { containing protein } 3\end{array}$ & & $-1,17$ & & & & & no human data \\
\hline Q9D172 & D10Jhu81e & ES1 protein homolog & $-2,04$ & 1,47 & $-1,40$ & & & & no human data \\
\hline
\end{tabular}

The color gradients of red (elevated protein level) to blue (reduced protein level) were used to show the differential abundances of APP/PS1 mitochondrial proteins (the numbers represent the average ratio values). Red text indicates the increased, and blue indicates the decreased protein levels in human $\mathrm{AD}$ brain or plasma samples ( $s m$ synaptic mitochondria, $n s m$ non-synaptic mitochondria; 3, 6, and 9: the age of animals in months). Green indicates the proteins that are already known as binding partners of $A \beta$ oligomer

common target proteins are protein kinases $(n=3)$, caspases $(n=2)$, a cytokine $(n=1)$, an oxidoreductase $(n=1)$, an electron transporter $(n=1)$, or anti-apoptotic proteins $(n=2)$ (Fig. 6b). Target proteins showing remarkably high number of relationships were glyceraldehyde-3- phosphate dehydrogenase (GAPDH), apoptosis regulator Bcl-2 (oxidoreductase BCL2), anti-apoptotic protein, and cytochrome c (Cycs) electron transporter (9, 10, and 11 relationships, respectively, with the altered mitochondrial proteins).

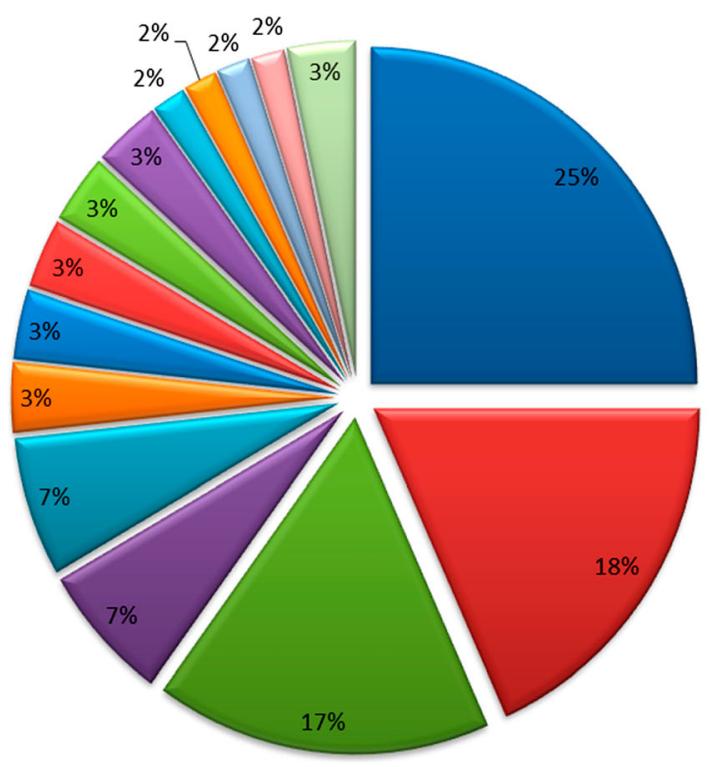

$\square$ electron transport chain
$\square$ tricarboxylic acid cycle
$\square$ oxidative stress and apoptosis
$\square$ protein synthesis and folding
$\square$ nucleotide metabolism
$\square$ protein transport
$\square$ glycolysis and gluconeogenesis
$\square$ ketone body metabolism
$\square$ lipid metabolism
$\square$ amino acid metabolism
$\square$ lactate metabolism
$\square$ glutathione metabolism
$\square$ synaptic transmission
$\square$ signal transduction
$\square$ unknown function

Fig. 3 Functional clustering of mitochondrial protein changes 


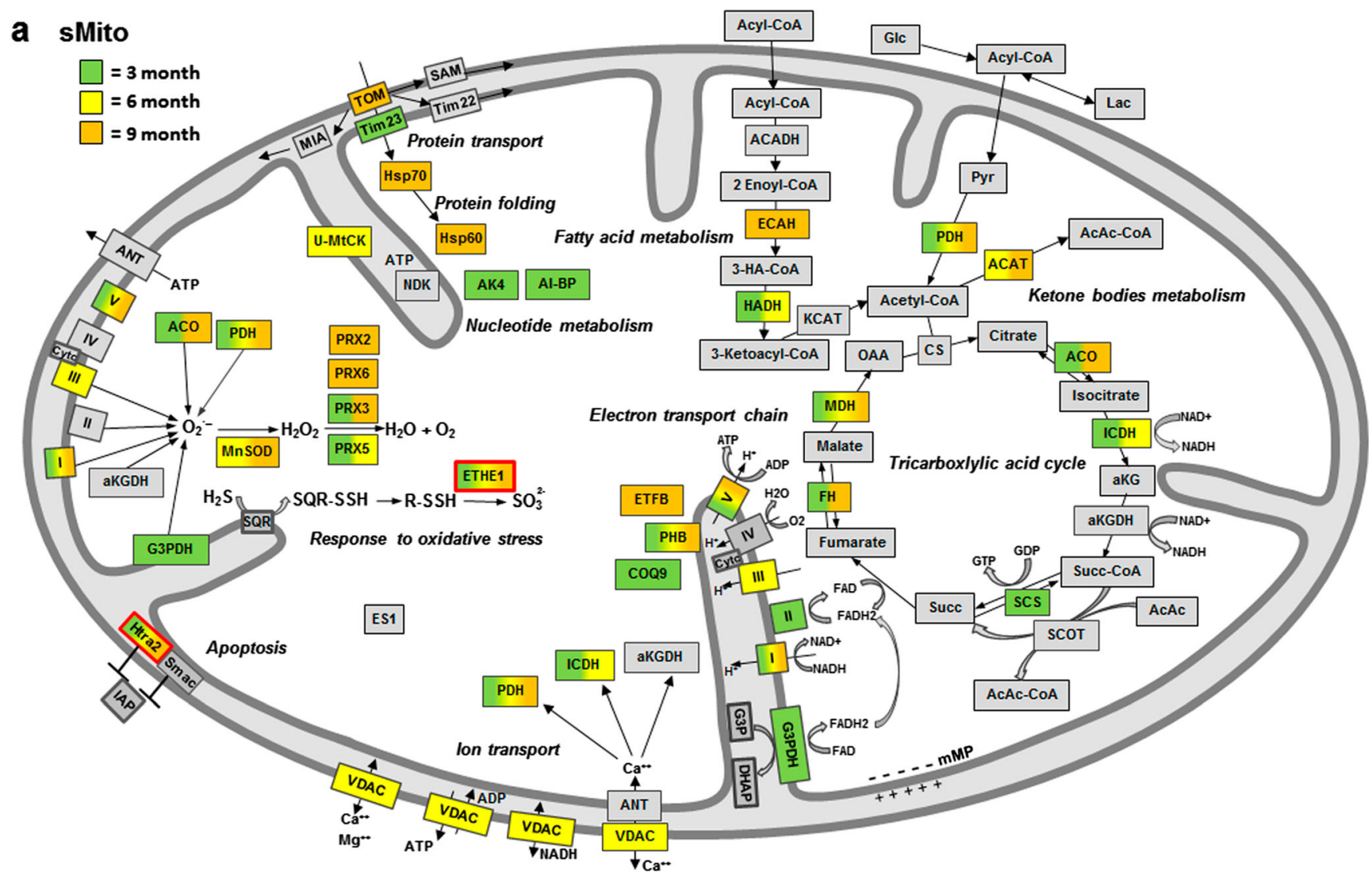

\section{b nsMito}

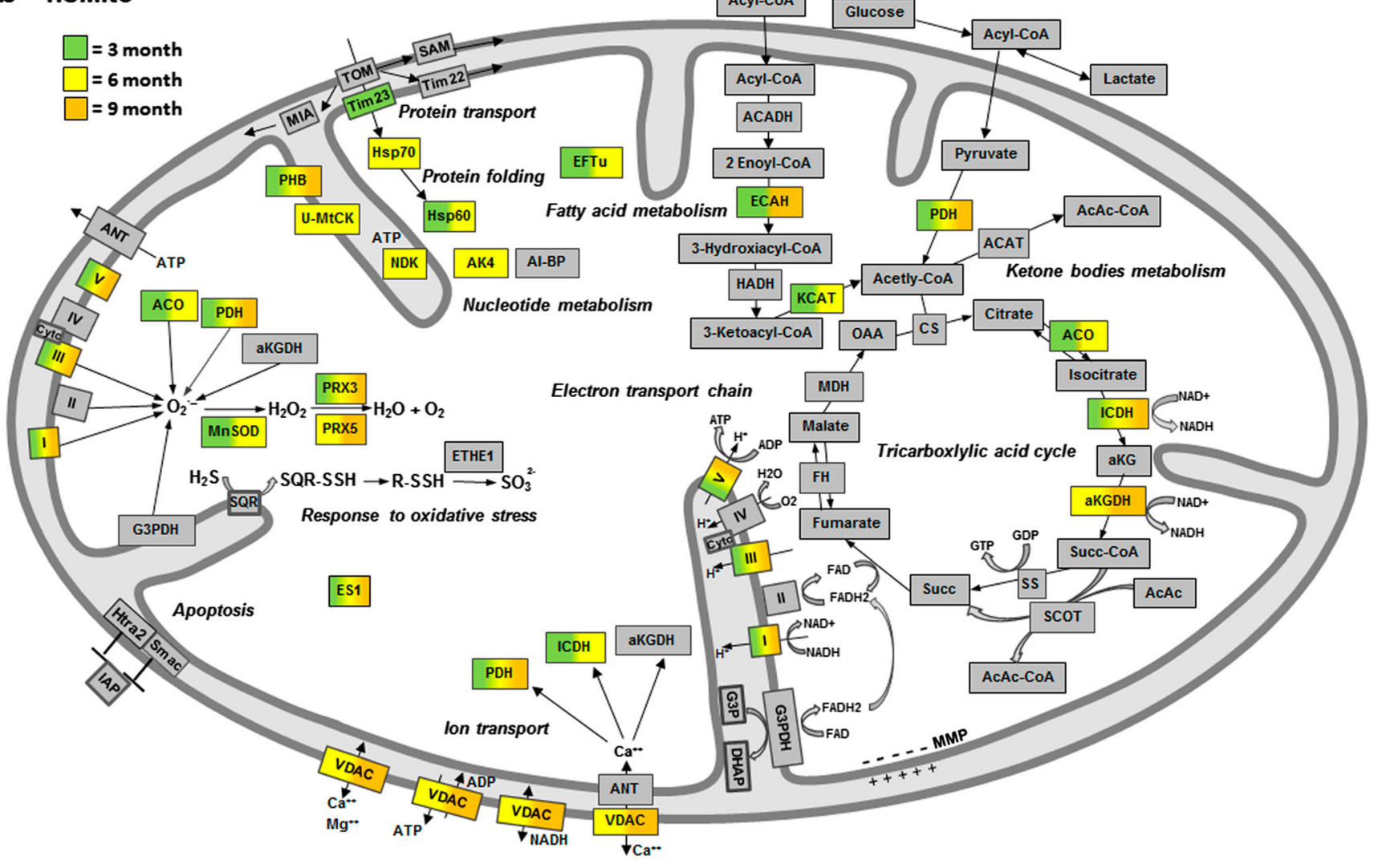


Fig. 4 Mitochondrial localization of altered synaptic (a) and non-synaptic (b) mitochondrial proteins in 3-, 6-, and 9-month-old APP/PS1 brain. Green, yellow, and orange background indicates proteins from 3-, 6-, and 9-month-old APP/PS1 animals, respectively. Protein transport: TOM translocase of the outer membrane, $\operatorname{Tim} 23$ translocase of the inner membrane subunit 23, MIA mitochondrial intermembrane space assembly, SAM sorting and assembly machinery, Tim 22 translocase of the inner membrane subunit 22. Protein synthesis and folding: Hsp70 $70 \mathrm{kDa}$ heat shock protein, Hsp60 $60 \mathrm{kDa}$ heat shock protein, EFTu elongation factor Tu. Nucleotide metabolism: $A K 4$ adenylate kinase 4, NDK nucleoside diphosphate kinase, $U-M t C K$ ubiquitous mitochondrial creatine kinase. Electron transport chain: I complex I, II complex II, III complex III, Cytc cytochrome complex, IV complex IV, $V$ complex V. Tricarboxylic acid cycle: $C S$ citrate synthase, $A C O$ aconitase, $I C D H$ isocitrate dehydrogenase, $a K G$ alpha-ketoglutarate, $a K G D H$ alpha-ketoglutarate dehydrogenase, Succ-CoA succinyl-CoA, AcAc acetoacetate, AcAc-CoA acetoacetyl-CoA, SCOT succinyl-CoA:3-ketoacid CoA transferase, Succ succinate, $F H$ fumarate hydratase, $M D H$ malate dehydrogenase, $O A A$ oxaloacetic acid. Ketone body metabolism: ACAT acetyl-CoA acetyltransferase. Fatty acid metabolism: ACADH acyl-CoA dehydrogenase, ECAH enoyl-CoA hydratase, HADH hydroxyacylcoenzyme A dehydrogenase, KCAT 3-ketoacyl-CoA transferase. Apoptosis: Htra2 serine protease HTRA2, Smac second mitochondriaderived activator of caspases. Oxidative stress: $M n S O D$ manganese superoxide dismutase, $P R X 3$ peroxiredoxin $3, P R X 5$ peroxiredoxin 5 , ETHE1 persulfide dioxygenase ETHE1. Ion transport: ANT adenine nucleotide translocase

\section{Validation of Htra2 and Ethe1 Protein Changes with WB}

For WB analysis, sMito samples were used from APP/PS1 and B6 animals. Htra2 and Ethe1 levels were analyzed in 3- and 6-month-old sMito samples ( $n=6$ samples per group). The densitometry data of protein band intensities were analyzed with ImageJ software (NIH, Bethesda). The protein levels of Htra2 in 3- $(0.68 \pm 0.08)$ and 9-month-old APP/PS1 mice $(0.70 \pm 0.06)$ were significantly decreased $(p<0.001)$, while the protein levels of Htra2 in 6-month-old APP/PS1 mice $(1.28 \pm 0.07)$ were significantly increased $(p<0.001)$, compared to B6 mice. Similar to the dynamic of Htra2 protein changes, the protein levels of Ethe1 in 3- $(0.74 \pm 0.08)$ and 9month-old APP/PS1 mice $(0.68 \pm 0.05)$ were significantly decreased $(p<0.001)$, while the protein levels of Htra2 in 6month-old APP/PS1 mice $(1.51 \pm 0.16)$ were significantly increased ( $p<0.001)$, compared to B6 mice. Thus, the WB results of these proteins confirmed the 2D-DIGE data (Fig. 5). The normalized Htra2 and Ethe protein levels (APP/B6 densitometric value) were significantly increased in 6-month-old compared to 3-month-old mice. Furthermore, both proteins were significantly decreased by 9 months compared to 6 months of age $(p<0.001)$ (Fig. 7).

\section{Discussion}

We present here the first comprehensive study of protein network changes in sMito and nsMito at different ages of progression of APP and A $\beta$ accumulation in APP/PS1 mice. Significant changes of 60 different mitochondrial proteins a
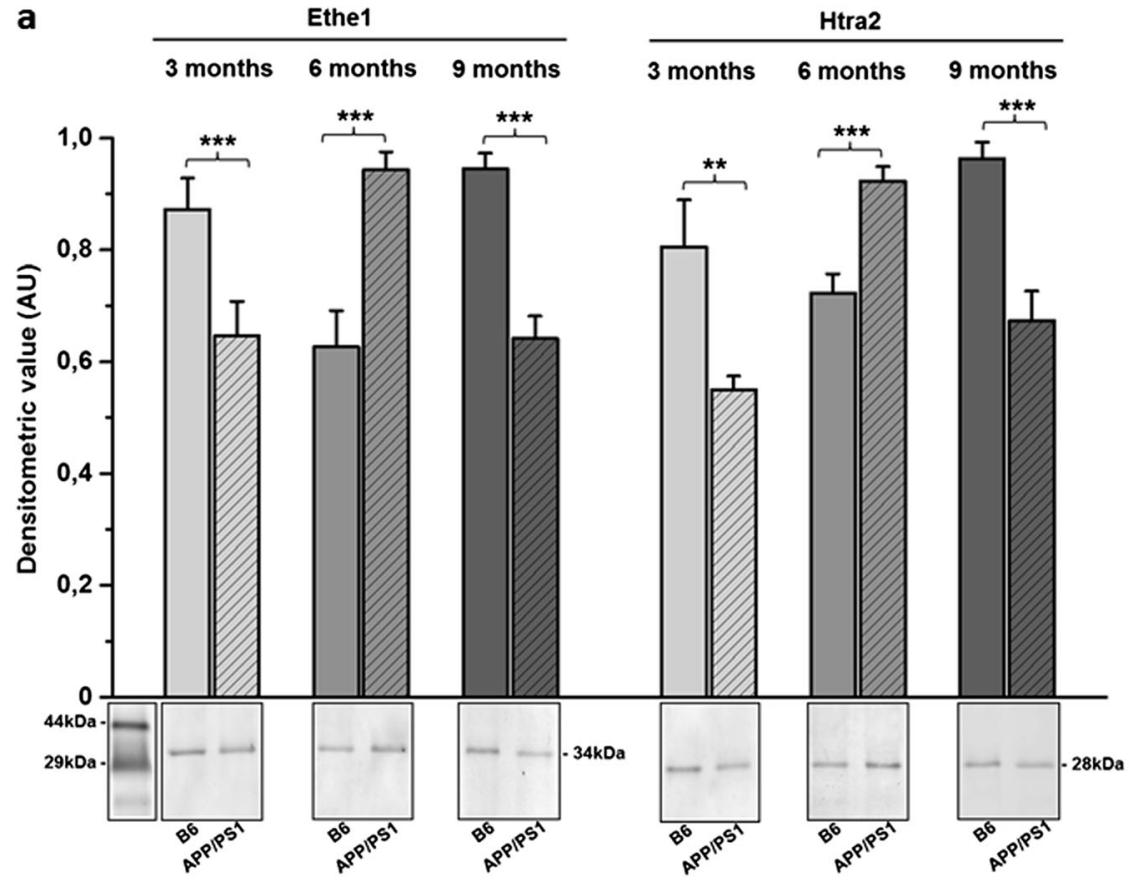

b

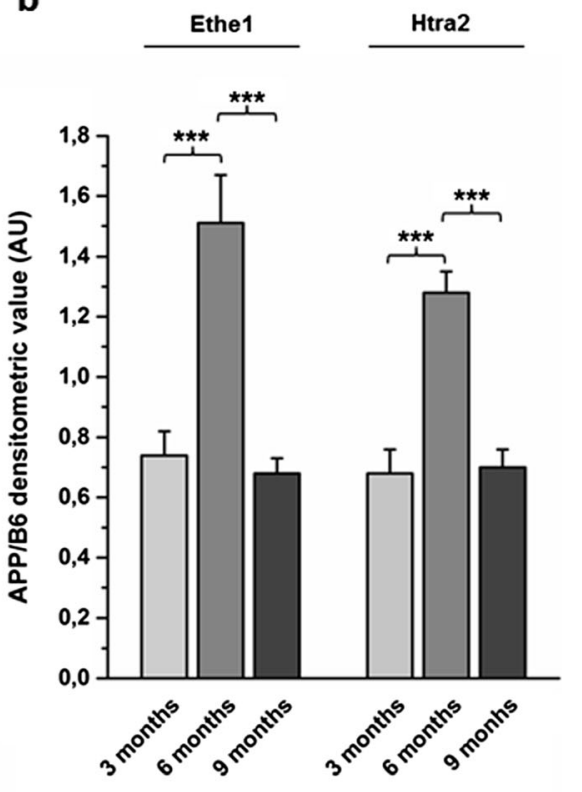

Fig. 5 Western blot validation of changes in Ethe1 and Htra2 expression in synaptic mitochondria of 3-, 6-, and 9-month-old APP/PS1 mice. Densitometric analysis was performed for Ethe1 and Htra2 $(n=6)$. The levels of Ethe1 and Htra2 were significantly decreased in synaptic mitochondria of 3 and 9 , while significantly increased in 6-month-old APP/PS1 mice. Representative immunopositive bands are shown under the diagram. (Student's $t$ tests, $* * * p<0.001 ; * * p<0.01$; error bars indicate SEM) 


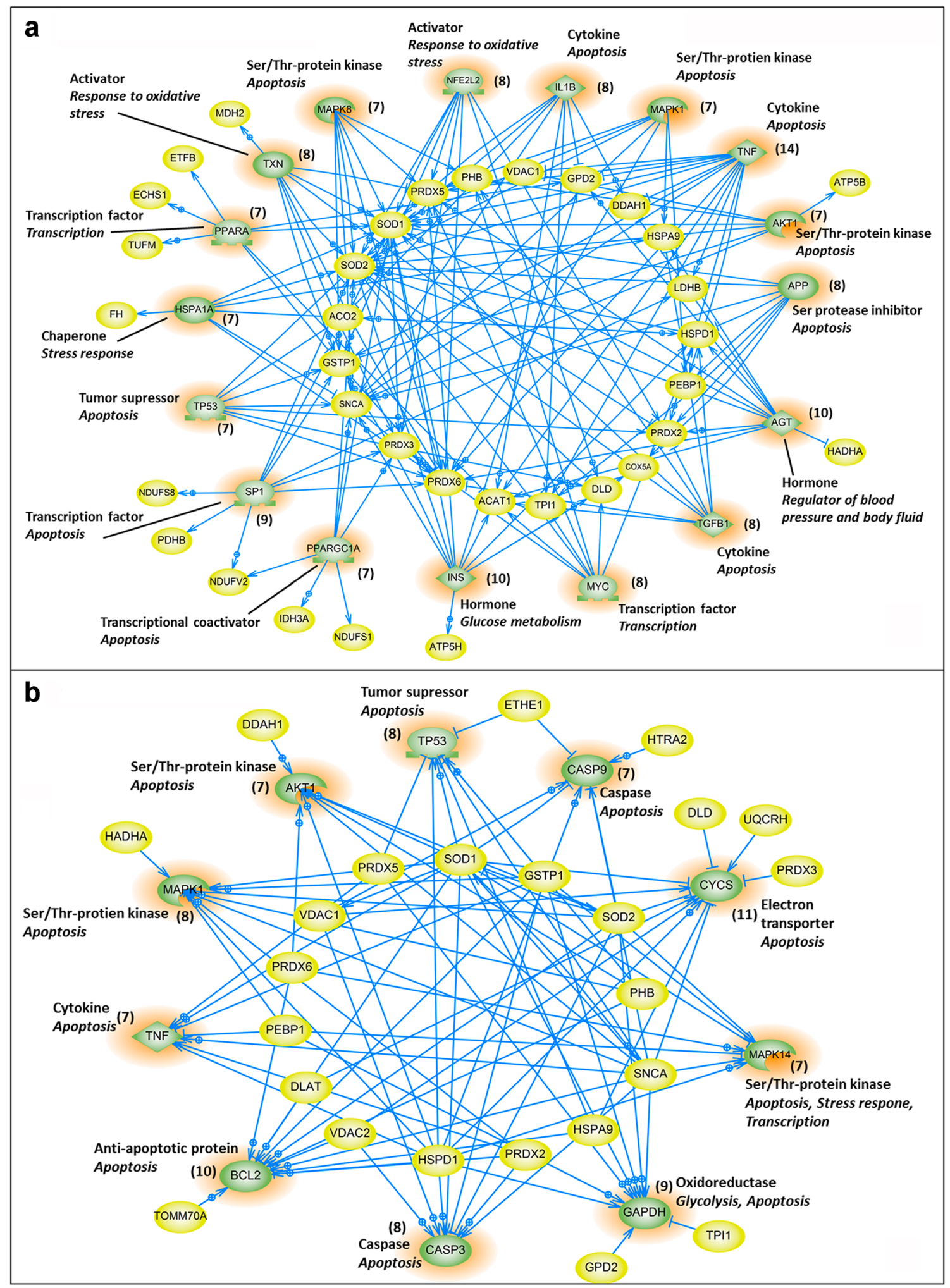


Fig. 6 Common regulator (a) and target (b) analysis of altered mitochondrial proteins. Blue edges indicate the relationships between common regulators/targets and altered mitochondrial proteins. Yellow indicates mitochondrial proteins that were significantly changed and have common targets or regulators (full protein names are present in Table 1). Green indicates the common regulator (a) or target (b) proteins. NFE2L2 nuclear factor erythroid 2-related factor 2, ILIB interleukin-1 beta, MAPK1 mitogen-activated protein kinase $1, T N F$ tumor necrosis factor, $A K T 1$ RACalpha serine/threonine-protein kinase, $A P P$ amyloid beta A4 protein, $A G T$ angiotensinogen, TGFB1 transforming growth factor beta-1, $M Y C$ myc proto-oncogene protein, INS insulin, PPARGCIA peroxisome proliferatoractivated receptor gamma coactivator 1-alpha, $S P 1$ transcription factor Sp1, TP53 cellular tumor antigen $\mathrm{p} 53, H S P A 1 A$ heat shock $70 \mathrm{kDa}$ protein $1 \mathrm{~A} /$ 1B, PPARA peroxisome proliferator-activated receptor alpha, $T X N$ thioredoxin, $M A P K 8$ mitogen-activated protein kinase $8, C A S P 9$ caspase9, CYCS cytochrome c, MAPK14 mitogen-activated protein kinase 14, GAPDH glyceraldehyde-3-phosphate dehydrogenase, CASP3 caspase-3, $B C L 2$ apoptosis regulator $\mathrm{Bcl}-2$

were identified by comparing of APP/PS1 to B6 mice (Table 1). The majority of significant protein changes were related to energy metabolism (ETC and TCA cycle), oxidative stress response, and apoptosis.

Based on common regulator and target analysis of altered proteins of sMito and nsMito, we conclude that regulator and target proteins being in direct interaction with proteins changed in APP/PS1 mice are involved in inflammation and apoptotic pathways (Fig. 6). TNF as a common regulator and target has the highest number of relationships suggesting a pivotal role of TNF in $A \beta-$ mediated mitochondrial protein changes in parallel with $\mathrm{A} \beta$ accumulation in the mitochondria. TNF is a proinflammatory cytokine, which is a key initiator of inflammation in the brain and is also involved in neurotoxicity, neuronal death, and dysfunction [35]. Increasing amount of data suggests the involvement of TNF in human AD. $\mathrm{A} \beta$ was found to stimulate secretion of TNF [36, 37] and other inflammatory mediators in the brain [38, 39]. Furthermore, $A \beta$-induced neuroinflammation is an early step in neurodegeneration [40]. In accordance with the results of animal model studies, a 25 -fold elevation of TNF level was observed in the cerebrospinal fluid of AD patients [41]. TNF level is in good correlation with clinical progression of AD [42]. Inhibition of TNF signaling prevents pre-plaque $A \beta$-associated neuropathology [43], while an anti-TNF therapy efficiently improved the cognition of AD patients [44-46]. Our results suggest that TNF contributes to early appearance of mitochondrial proteome changes. We raise the possibility that TNF could be an early indicator of initial phase of $A \beta$ accumulation; however, it should be tested in human $\mathrm{AD}$ subjects in a non-invasive manner. The results of bioinformatics studies in APP/PS1 mice model proteomics revealed that TNF- $\alpha$-induced extrinsic and Htra2-, Ethe1-, phosphatidylethanolamine-binding protein 1

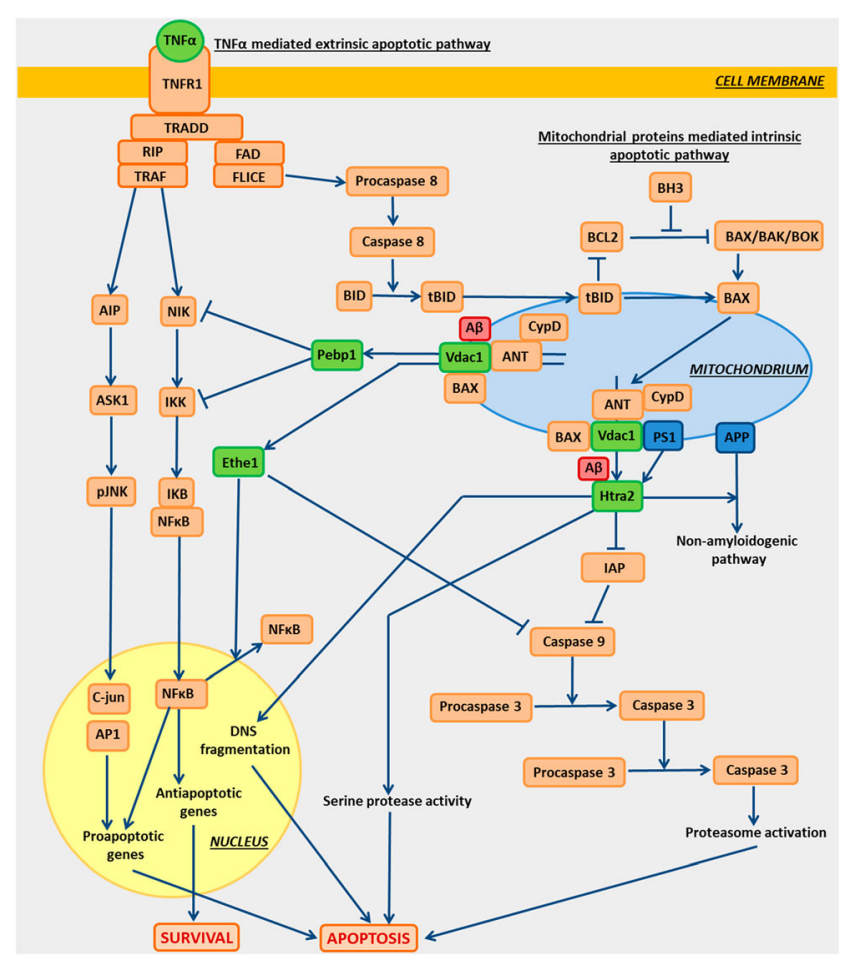

Fig. 7 The TNF- $\alpha$ (common regulator and target protein)-induced extrinsic and the A $\beta$-mediated Htra2-, Ethe1-, Pebp1-, and Vdac1related mitochondrial apoptotic pathway connections. The regulation pathways suggest the importance of $A \beta$ effect on NF$\mathrm{KB}$ signaling and caspase cascade pathways. AIP ASK1-interacting protein 1, $A S K 1$ apoptosis-signal-regulating kinase-1, $B I D$ Bcl-2 $\mathrm{B}$ cell lymphoma 2 agonist, $t B I D$ truncated BID, $B A X$ B cell lymphoma 2-associated protein $\mathrm{X}, p J N K$ phospho c-Jun amino (N) terminal kinase, $A P 1$ activator protein-1, c-jun c-Jun amino (N) terminal kinase, $C y p D$ cyclophilin-D, Ethe1 persulfide dioxygenase Ethe1, FAD FAS-associated death domain, FLICE FADD-like interleukin-1 $\beta$, Htra2 serine protease Htra2, NIK NFkappaB-inducing kinase, IKK IkappaB kinase, $I \kappa B$ inhibitory subunit of NF-kB, IAP inhibitor of apoptosis, Pebpl phosphatidylethanolamine-binding protein 1, PS1 presenilin-1, RIP receptor-interacting protein, TNFRI TNF receptor 1 , TRADD TNF-receptor death domain, TRAF: TNF-associated factor 2, Vdac1: Voltage-dependent anion-selective channel protein-1. According to [47-51] and own data

(Pebp1)-, and Vdac1-related mitochondrial apoptotic pathways suggest the importance of $A \beta$ effect on nuclear factor kappa $\mathrm{B}(\mathrm{NF}-\mathrm{KB})$ signaling and caspase cascade pathways (Fig. 7).

Htra2 is a member of the high-temperature requirement (HtrA) family of oligomeric serine proteases, participating in several cellular processes including mitochondrial function, autophagy, and apoptosis. Several studies have demonstrated the essential role of Htra2 in pathogenesis of Parkinson's disease [52, 53], but its role in $\mathrm{AD}$ is not clear. Enzymatic activity of Htra2 increases in frontal cortex of AD patients [28]; moreover, Htra2 accumulates in the cerebral cortex and hippocampus and is also present in senile plaques and 
neurofibrillary tangles [54]. Furthermore, APP is directly cleaved by the Htra2 $[55,56]$. Htra2 also interacts with $\mathrm{A} \beta$, contributing to its proapoptotic activity [57]. The Htra2-mediated processing of APP is a physiological process in normal brain [55]. Mitochondrial Htra2 could interact with PS1 [47, 58-61]. PS1-derived peptides binding to the PDZ domain of Htra2 can induce apoptosis [47] (Fig. 7). In conclusion, increased Htra2 level enhances Htra2-mediated APP processing that counterbalances the amyloidogenic cleavage of APP. This mechanism might slow down accumulation of $A \beta$ in the 6-month-old APP/PS1 mice. In this way, Htra2 increase could represent a temporary protective mechanism against further $A \beta$ overexpression at the 6-monthold mice.

Ethel plays an essential role in hydrogen sulfide catabolism. Ethe1 is an anti-apoptotic protein, which increases the deacetylase activity of p53 in association with histone deacetylase 1 leading to the suppression of apoptosis [62]. Ethe1 also inhibits NF- $\mathrm{kB}$ signaling by binding to RelA and accelerating its export from the nucleus [48] (Fig. 7). Loss of Ethe1 causes fatal sulfide toxicity in ethylmalonic encephalopathy which is an autosomal recessive, invariably fatal disorder [63]. The role of $A \beta$ accumulation-induced pathomechanism has not yet been described. According to our data-driven working hypothesis, the increased Ethe1 level in 6month-old sMito might prevent $\mathrm{A} \beta$-induced apoptotic processes that could be a compensatory mechanism against moderate amyloid accumulation.

Pebpl (also known as Raf kinase inhibitor protein (RKIP)) is a multifunctional protein. It is the precursor of hippocampal cholinergic neuro-stimulating peptide (HCNP). In our study, Pebp1 showed decreased protein expression in the 9-month-old mouse only, where amyloid plaques are present in the brain. Many studies showed that Pebp1 plays a pivotal modulatory role in different signaling cascades. It inhibits the MAPK signaling pathway Ras/Raf-1/MEK/ERK by inhibition of Raf-1 phosphorylation and activation [64] and, moreover, inhibits TNF- $\alpha$-induced activation of the NF- $\mathrm{kB}$ pathway [49] (Fig. 7). The expression of Pebp 1 mRNA was decreased in the hippocampal CA1 field in patients of late-onset AD. Since HCNP stimulates the enzymatic activity of choline acetyltransferase in neurons, its low concentration in $\mathrm{AD}$ patients because of its decreased precursor Pebp1 could explain the downregulation of cholinergic neurons associated with the memory loss in AD [65]. We note here that Pebp1 decreases in another AD model mouse Tg2576 in accordance with development of amyloid plaques [66]. Our data confirm importance of Pebp1 in AD pathogenesis in APP/PS1 mice model.
Voltage-dependent anion-selective channel proteins (VDACS) are pore-forming proteins found in the mitochondrial membrane of all eukaryotes and postsynaptic membranes in the brain. Our results demonstrated that Vdac1 decreased in 6-month-old APP/PS1 mice synaptic mitochondria samples, while increased in 9-month-old ones. The non-synaptic mitochondrial Vdac1 showed changes in both directions in different protein spots. VDACs regulate anion fluxes of metabolites including ATP and regulate mitochondrial metabolism. In human postmortem brains of AD subjects, Vdac1 was significantly reduced in temporal and frontal cortex and thalamus [67]. Other experiments demonstrated that Vdac1 is elevated in $\mathrm{AD}$ affected regions of postmortem brains and cortical tissues of APP transgenic mice. Vdac1 is linked to $A \beta$ and phosphorylated tau in human postmortem brains of $\mathrm{AD}$ patients and different $\mathrm{AD}$ mouse models. Vdac1 increase blocks the mitochondrial permeability transition (MPT) pores, disrupts the transport of mitochondrial proteins and metabolites, impairs gating of VDAC, and causes defects in oxidative phosphorylation, leading to mitochondrial dysfunction in AD neurons [68-70] (Fig. 7). Vdac1 is also overexpressed in the hippocampus of amyloidogenic $\mathrm{AD}$ transgenic mice models. Furthermore, soluble $A \beta$ oligomers were able to induce upregulation of Vdac1 in a human neuroblastoma cell line [70]. Reduced Vdac1 expression may be beneficial to synaptic activity, may improve function, and may protect against toxicities of AD-related genes including A $\beta P P$, Tau, PS1, PS2, and BACE1 [71]. In detergent-resistant membranes, Vdac1 also associates with $\gamma$-secretase and affects $A \beta$ production, suggesting that VDAC is a putative target for drug development against $\mathrm{AD}$ [72]. In conclusion, the decreased synaptic mitochondrial Vdac1 level in 6 months of age APP/PS1 mice may improve synaptic function, while increased level in older age might correlate with synaptic loss and memory impairment.

It is important to note that beside $A \beta$, an increasing level of AICD peptide could also mediate several processes in APP/PS1 mice. Although AICD can be generated by both $\alpha-\gamma$ and $\beta-\gamma$-secretase cleavages, its exact role remains controversial [73]. The AICD-mediated nuclear signaling occurs predominantly through the amyloidogenic processing pathway [74]. Moreover, AICD can interact with different intracellular adaptor proteins as signaling molecules [75]. AICD can translocate to the nucleus, forms multiprotein complexes, and regulates its own precursor's expression (APP) [76]. Furthermore, AICD acts as a positive regulator of apoptosis [77-79] and modulates inflammation-associated calcium homeostasis and ATP metabolism linked to mitochondrial bioenergetics function [80]. APP and AICD 
also increase the expression of mitochondrial proteins, such as mitochondrial master transcriptional coactivator PGC-1a and its target genes [81], so APP processing may also regulate synaptic and non-synaptic mitochondrial protein changes in APP/PS1 mice.

One of the main interests of AD research nowadays is to find early markers to select and cluster high-risk people, which could be the first step for causal treatment of AD. Our results revealed some early changes of mitochondrial proteome that are present before any neurological symptoms of $\mathrm{AD}$ appear. To estimate the translational value of our findings, it is noteworthy that 46 out of the 60 altered proteins have already been known to change in the late stage of human $\mathrm{AD}$ (Table 1/Human AD brain column, established from postmortem or autopsy confirmed AD samples). We identified 11 proteins already known as direct binding partners of human $A \beta$ oligomers (Table 1/green labeling) [72], suggesting that binding of $A \beta$ to mitochondrial proteins is a major mechanism of its metabolic action.

In summary, our results demonstrate a different and agedependent effect on synaptic and non-synaptic mitochondrial proteome in APP/PS1 mouse model of APP overproduction and $A \beta$ accumulation. The majority of the significant protein changes were related to energy metabolism, oxidative stress response, and apoptosis. Although the levels of several mitochondrial proteins were altered at early stage, no simultaneous alteration in hydrogen peroxide generation could be detected. This indicates functional compensation of protein changes in early stage. Htra2 and Ethe1 apoptotic proteins show an age-dependent change in expression in sMito of APP/PS1 mice; thus, they could be used as progression markers of $A \beta$ accumulation. The result of bioinformatical analysis suggests a regulatory role of TNF in $\mathrm{A} \beta$-mediated mitochondrial protein changes. Our findings also suggest that the translational value of the results with mice is not negligible. Based on these findings in mice, we suggest conducting research for early tests of Htra2, Ethe1, Vdac1, Pebp1, and TNF level in further independent models (like other transgenic mammal models or mutant cell lines), together with in human CSF or plasma which could lead to the establishment of early biomarkers of high-risk population. We hope to open a new path of research aiming early mitochondrial molecular mechanisms of $A \beta$ accumulation as a prodromal stage of human AD.

Acknowledgments This work was supported by the KTIA NAP B 13-2-2014-0004, KTIA_NAP_13-2-2015-0003, and KTIA_NAP_B_132-2014-0017 programs, a Gedeon Richter Pharmaceutical basic ${ }^{-}$research grant.

\section{References}

1. Kim I, Xu W, Reed JC (2008) Cell death and endoplasmic reticulum stress: disease relevance and therapeutic opportunities. Nat Rev Drug Discov 7(12):1013-1030

2. Kovacs G (2014) Current concepts of neurodegenerative disease. EMJ Neurology 1:78-86

3. Roussel BD et al (2013) Endoplasmic reticulum dysfunction in neurological disease. Lancet Neurol 12(1):105-118

4. Chavez-Gutierrez L et al (2012) The mechanism of gammasecretase dysfunction in familial Alzheimer disease. EMBO J 31(10):2261-2274

5. Lam B et al (2013) Clinical, imaging, and pathological heterogeneity of the Alzheimer's disease syndrome. Alzheimers Res Ther 5(1):1

6. Price JL et al (2009) Neuropathology of nondemented aging: presumptive evidence for preclinical Alzheimer disease. Neurobiol Aging 30(7):1026-1036

7. Morris GP, Clark IA, Vissel B (2014) Inconsistencies and controversies surrounding the amyloid hypothesis of Alzheimer's disease. Acta Neuropathol Commun 2:135

8. Reddy PH, Beal MF (2008) Amyloid beta, mitochondrial dysfunction and synaptic damage: implications for cognitive decline in aging and Alzheimer's disease. Trends Mol Med 14(2):45-53

9. Hoxha E et al (2012) Excitability and synaptic alterations in the cerebellum of APP/PS1 mice. PLoS One 7(4):e34726

10. Eckert A et al (2008) Soluble beta-amyloid leads to mitochondrial defects in amyloid precursor protein and tau transgenic mice. Neurodegener Dis 5(3-4):157-159

11. Weidemann A et al (2002) A novel epsilon-cleavage within the transmembrane domain of the Alzheimer amyloid precursor protein demonstrates homology with Notch processing. Biochemistry 41(8):2825-2835

12. Ashe KH (2005) Mechanisms of memory loss in Abeta and tau mouse models. Biochem Soc Trans 33(Pt 4):591-594

13. Takahashi RH et al (2002) Alzheimer beta-amyloid peptides: normal and abnormal localization. Histol Histopathol 17(1):239-246

14. Devi L et al (2006) Accumulation of amyloid precursor protein in the mitochondrial import channels of human Alzheimer's disease brain is associated with mitochondrial dysfunction. J Neurosci 26(35):9057-9068

15. Manczak M et al (2006) Mitochondria are a direct site of A beta accumulation in Alzheimer's disease neurons: implications for free radical generation and oxidative damage in disease progression. Hum Mol Genet 15(9): 1437-1449

16. Caspersen $\mathrm{C}$ et al (2005) Mitochondrial Abeta: a potential focal point for neuronal metabolic dysfunction in Alzheimer's disease. FASEB J 19(14):2040-2041

17. Du H et al (2010) Early deficits in synaptic mitochondria in an Alzheimer's disease mouse model. Proc Natl Acad Sci U S A 107(43):18670-18675

18. Moreira PI et al (2010) Mitochondria: a therapeutic target in neurodegeneration. Biochim Biophys Acta 1802(1):212-220

19. Su B et al (2010) Abnormal mitochondrial dynamics - a novel therapeutic target for Alzheimer's disease? Mol Neurobiol 41(23):87-96

20. Swerdlow RH (2011) Brain aging, Alzheimer's disease, and mitochondria. Biochim Biophys Acta 1812(12):1630-1639

21. Butterfield DA, Castegna A (2003) Proteomic analysis of oxidatively modified proteins in Alzheimer's disease brain: insights into neurodegeneration. Cell Mol Biol (Noisy-le-Grand) 49(5):747-751

22. Shiozaki A et al (2004) Proteome analysis of brain proteins in Alzheimer's disease: subproteomics following sequentially extracted protein preparation. J Alzheimers Dis 6(3):257-268 
23. Gillardon F et al (2007) Proteomic and functional alterations in brain mitochondria from Tg2576 mice occur before amyloid plaque deposition. Proteomics 7(4):605-616

24. Sizova D et al (2007) Proteomic analysis of brain tissue from an Alzheimer's disease mouse model by two-dimensional difference gel electrophoresis. Neurobiol Aging 28(3):357-370

25. Kim SH et al (2001) The reduction of NADH ubiquinone oxidoreductase 24- and 75-kDa subunits in brains of patients with Down syndrome and Alzheimer's disease. Life Sci 68(24):2741-2750

26. Kim SH et al (2002) Human brain nucleoside diphosphate kinase activity is decreased in Alzheimer's disease and Down syndrome. Biochem Biophys Res Commun 296(4):970-975

27. Bubber $\mathrm{P}$ et al (2005) Mitochondrial abnormalities in Alzheimer brain: mechanistic implications. Ann Neurol 57(5):695-703

28. Westerlund $\mathrm{M}$ et al (2011) Altered enzymatic activity and allele frequency of OMI/HTRA2 in Alzheimer's disease. FASEB J 25(4):1345-1352

29. Zahid S et al (2014) Differential expression of proteins in brain regions of Alzheimer's disease patients. Neurochem Res 39(1): 208-215

30. Jankowsky JL et al (2004) Mutant presenilins specifically elevate the levels of the 42 residue beta-amyloid peptide in vivo: evidence for augmentation of a 42 -specific gamma secretase. Hum Mol Genet 13(2):159-170

31. Gimbel DA et al (2010) Memory impairment in transgenic Alzheimer mice requires cellular prion protein. J Neurosci 30(18):6367-6374

32. Volgyi K et al (2015) Synaptic mitochondria: a brain mitochondria cluster with a specific proteome. J Proteomics 120:142-157

33. Szego EM et al (2010) A mouse model of anxiety molecularly characterized by altered protein networks in the brain proteome. Eur Neuropsychopharmacol 20(2):96-111

34. Kekesi KA et al (2012) Altered functional protein networks in the prefrontal cortex and amygdala of victims of suicide. PLoS One 7(12): e50532

35. Feldmann M, Maini RN (2003) Lasker Clinical Medical Research Award. TNF defined as a therapeutic target for rheumatoid arthritis and other autoimmune diseases. Nat Med 9(10):1245-1250

36. Klegeris A, Walker DG, McGeer PL (1997) Interaction of Alzheimer beta-amyloid peptide with the human monocytic cell line THP-1 results in a protein kinase C-dependent secretion of tumor necrosis factor-alpha. Brain Res 747(1):114-121

37. Combs CK et al (2001) beta-Amyloid stimulation of microglia and monocytes results in TNFalpha-dependent expression of inducible nitric oxide synthase and neuronal apoptosis. J Neurosci 21(4): $1179-1188$

38. Rosenberg PB (2005) Clinical aspects of inflammation in Alzheimer's disease. Int Rev Psychiatry 17(6):503-514

39. Ralay Ranaivo H et al (2006) Glia as a therapeutic target: selective suppression of human amyloid-beta-induced upregulation of brain proinflammatory cytokine production attenuates neurodegeneration. J Neurosci 26(2):662-670

40. Craft JM, Watterson DM, Van Eldik LJ (2006) Human amyloid beta-induced neuroinflammation is an early event in neurodegeneration. Glia 53(5):484-490

41. Tarkowski E et al (2003) Cerebral pattern of pro- and antiinflammatory cytokines in dementias. Brain Res Bull 61(3):255-260

42. Tarkowski $\mathrm{E}$ et al (2003) Intrathecal inflammation precedes development of Alzheimer's disease. J Neurol Neurosurg Psychiatry 74(9):1200-1205

43. McAlpine FE et al (2009) Inhibition of soluble TNF signaling in a mouse model of Alzheimer's disease prevents pre-plaque amyloid-associated neuropathology. Neurobiol Dis 34(1):163-177

44. Tobinick E et al (2006) TNF-alpha modulation for treatment of Alzheimer's disease: a 6-month pilot study. MedGenMed 8(2):25
45. Tweedie D, Sambamurti K, Greig NH (2007) TNF-alpha inhibition as a treatment strategy for neurodegenerative disorders: new drug candidates and targets. Curr Alzheimer Res 4(4):378-385

46. Tobinick E (2009) Tumour necrosis factor modulation for treatment of Alzheimer's disease: rationale and current evidence. CNS Drugs 23(9):713-725

47. Gupta $\mathrm{S}$ et al (2004) The C-terminal tail of presenilin regulates Omi/HtrA2 protease activity. J Biol Chem 279(44):45844-45854

48. Higashitsuji $\mathrm{H}$ et al (2002) A novel protein overexpressed in hepatoma accelerates export of NF-kappa B from the nucleus and inhibits p53-dependent apoptosis. Cancer Cell 2(4):335-346

49. Yeung $\mathrm{KC}$ et al (2001) Raf kinase inhibitor protein interacts with NF-kappaB-inducing kinase and TAK1 and inhibits NF-kappaB activation. Mol Cell Biol 21(21):7207-7217

50. Benn SC, Woolf CJ (2004) Adult neuron survival strategiesslamming on the brakes. Nat Rev Neurosci 5(9):686-700

51. Shimizu $\mathrm{S}$ et al (2000) Electrophysiological study of a novel large pore formed by Bax and the voltage-dependent anion channel that is permeable to cytochrome $\mathrm{c}$. J Biol Chem 275(16):12321-12325

52. Strauss KM et al (2005) Loss of function mutations in the gene encoding Omi/HtrA2 in Parkinson's disease. Hum Mol Genet 14(15):2099-2111

53. Plun-Favreau $\mathrm{H}$ et al (2007) The mitochondrial protease $\mathrm{HtrA} 2$ is regulated by Parkinson's disease-associated kinase PINK1. Nat Cell Biol 9(11):1243-1252

54. Kawamoto $\mathrm{Y}$ et al (2010) Localization of HtrA2/Omi immunoreactivity in brains affected by Alzheimer's disease. Neuroreport 21(17):1121-1125

55. Park HJ et al (2006) Beta-amyloid precursor protein is a direct cleavage target of HtrA2 serine protease. Implications for the physiological function of HtrA2 in the mitochondria. J Biol Chem 281(45):34277-34287

56. Anandatheerthavarada HK et al (2003) Mitochondrial targeting and a novel transmembrane arrest of Alzheimer's amyloid precursor protein impairs mitochondrial function in neuronal cells. J Cell Biol 161(1):41-54

57. Park HJ et al (2004) Alzheimer's disease-associated amyloid beta interacts with the human serine protease HtrA2/Omi. Neurosci Lett 357(1):63-67

58. Gray CW et al (2000) Characterization of human HtrA2, a novel serine protease involved in the mammalian cellular stress response. Eur J Biochem 267(18):5699-5710

59. Martins LM et al (2002) The serine protease Omi/HtrA2 regulates apoptosis by binding XIAP through a reaper-like motif. J Biol Chem 277(1):439-444

60. Kuninaka S et al (2007) Serine protease Omi/HtrA2 targets WARTS kinase to control cell proliferation. Oncogene 26(17): 2395-2406

61. Behbahani $\mathrm{H}$ et al (2010) Association of Omi/HtrA2 with gammasecretase in mitochondria. Neurochem Int 57(6):668-675

62. Higashitsuji $\mathrm{H}$ et al (2007) Enhanced deacetylation of $\mathrm{p} 53$ by the anti-apoptotic protein HSCO in association with histone deacetylase 1. J Biol Chem 282(18):13716-13725

63. Tiranti V et al (2009) Loss of ETHE1, a mitochondrial dioxygenase, causes fatal sulfide toxicity in ethylmalonic encephalopathy. Nat Med 15(2):200-205

64. Fougner SL et al (2008) Low levels of raf kinase inhibitory protein in growth hormone-secreting pituitary adenomas correlate with poor response to octreotide treatment. J Clin Endocrinol Metab 93(4): 1211-1216

65. Maki M et al (2002) Decreased expression of hippocampal cholinergic neurostimulating peptide precursor protein mRNA in the hippocampus in Alzheimer disease. J Neuropathol Exp Neurol 61(2):176-185

66. George AJ et al (2006) Decreased phosphatidylethanolamine binding protein expression correlates with Abeta accumulation 
in the Tg2576 mouse model of Alzheimer's disease. Neurobiol Aging 27(4):614-623

67. Yoo BC et al (2001) Changes of voltage-dependent anion-selective channel proteins VDAC1 and VDAC2 brain levels in patients with Alzheimer's disease and Down syndrome. Electrophoresis 22(1):172-179

68. Reddy PH (2013) Is the mitochondrial outermembrane protein VDAC1 therapeutic target for Alzheimer's disease? Biochim Biophys Acta 1832(1):67-75

69. Manczak M, Reddy PH (2012) Abnormal interaction of VDAC1 with amyloid beta and phosphorylated tau causes mitochondrial dysfunction in Alzheimer's disease. Hum Mol Genet 21(23): 5131-5146

70. Cuadrado-Tejedor $M$ et al (2011) Enhanced expression of the voltage-dependent anion channel 1 (VDAC1) in Alzheimer's disease transgenic mice: an insight into the pathogenic effects of amyloid-beta. J Alzheimers Dis 23(2):195-206

71. Hur JY et al (2012) Identification of novel gamma-secretaseassociated proteins in detergent-resistant membranes from brain. J Biol Chem 287(15):11991-12005

72. Olah $\mathrm{J}$ et al (2011) Interactions of pathological hallmark proteins: tubulin polymerization promoting protein $/ \mathrm{p} 25$, beta-amyloid, and alpha-synuclein. J Biol Chem 286(39):34088-34100

73. Chang KA, Suh YH (2010) Possible roles of amyloid intracellular domain of amyloid precursor protein. BMB Rep 43(10):656-663

74. Goodger ZV et al (2009) Nuclear signaling by the APP intracellular domain occurs predominantly through the amyloidogenic processing pathway. J Cell Sci 122(Pt 20):3703-3714

75. Ramelot TA, Gentile LN, Nicholson LK (2000) Transient structure of the amyloid precursor protein cytoplasmic tail indicates preordering of structure for binding to cytosolic factors. Biochemistry 39(10):2714-2725

76. von Rotz RC et al (2004) The APP intracellular domain forms nuclear multiprotein complexes and regulates the transcription of its own precursor. J Cell Sci 117(Pt 19):4435-4448

77. Kinoshita A et al (2002) The gamma secretase-generated carboxyl-terminal domain of the amyloid precursor protein induces apoptosis via Tip60 in H4 cells. J Biol Chem 277(32):28530-28536

78. Ozaki $\mathrm{T}$ et al (2006) The intracellular domain of the amyloid precursor protein (AICD) enhances the p53-mediated apoptosis. Biochem Biophys Res Commun 351(1):57-63

79. Alves da Costa $\mathrm{C}$ et al (2006) Presenilin-dependent gammasecretase-mediated control of p53-associated cell death in Alzheimer's disease. J Neurosci 26(23):6377-6385

80. Hamid R et al (2007) Amyloid precursor protein intracellular domain modulates cellular calcium homeostasis and ATP content. $\mathrm{J}$ Neurochem 102(4):1264-1275

81. Robinson A et al (2014) Upregulation of PGC-1alpha expression by Alzheimer's disease-associated pathway: presenilin 1/amyloid precursor protein (APP)/intracellular domain of APP. Aging Cell 13(2):263-272

82. Reddy PH, Reddy TP (2011) Mitochondria as a therapeutic target for aging and neurodegenerative diseases. Curr Alzheimer Res 8(4):393-409

83. Gyorffy B et al (2013) Brain protein expression changes in WAG/ Rij rats, a genetic rat model of absence epilepsy after peripheral lipopolysaccharide treatment. Brain Behav Immun 35:86-95

84. Sorbi S, Bird ED, Blass JP (1983) Decreased pyruvate dehydrogenase complex activity in Huntington and Alzheimer brain. Ann Neurol 13(1):72-78

85. Raukas M et al (2012) Mitochondrial oxidative stress index, activity of redox-sensitive aconitase and effects of endogenous antiand pro-oxidants on its activity in control, Alzheimer's disease and Swedish Familial Alzheimer's disease brain. Free Radic Res 46(12):1490-1495
86. Perry EK et al (1980) Coenzyme A-acetylating enzymes in Alzheimer's disease: possible cholinergic 'compartment' of pyruvate dehydrogenase. Neurosci Lett 18(1):105-110

87. Gibson GE, Sheu KF, Blass JP (1998) Abnormalities of mitochondrial enzymes in Alzheimer disease. J Neural Transm 105(8-9): $855-870$

88. Kim SH et al (2001) The reduction of NADH Ubiquinone oxidoreductase 24-and 75-kDa subunits in brains of patients with Down syndrome and Alzheimer's disease. Life Sci 68(24):2741-2750

89. George AJ et al (2010) A serial analysis of gene expression profile of the Alzheimer's disease Tg2576 mouse model. Neurotox Res 17(4):360-379

90. Maurer I, Zierz S, Moller HJ (2000) A selective defect of cytochrome c oxidase is present in brain of Alzheimer disease patients. Neurobiol Aging 21(3):455-462

91. Mancuso M et al (2003) Decreased platelet cytochrome c oxidase activity is accompanied by increased blood lactate concentration during exercise in patients with Alzheimer disease. Exp Neurol 182(2):421-426

92. Parker WD Jr et al (1994) Reduced platelet cytochrome c oxidase activity in Alzheimer's disease. Neurology 44(6):1086-1090

93. Terni B et al (2010) Mitochondrial ATP-synthase in the entorhinal cortex is a target of oxidative stress at stages I/II of Alzheimer's disease pathology. Brain Pathol 20(1):222-233

94. Chandrasekaran K et al (1997) Decreased expression of nuclear and mitochondrial DNA-encoded genes of oxidative phosphorylation in association neocortex in Alzheimer disease. Brain Res Mol Brain Res 44(1):99-104

95. Burte $\mathrm{F}$ et al (2011) Alterations in the mitochondrial proteome of neuroblastoma cells in response to complex 1 inhibition. J Proteome Res 10(4):1974-1986

96. Doecke JD et al (2012) Blood-based protein biomarkers for diagnosis of Alzheimer disease. Arch Neurol 69(10):1318-1325

97. Krapfenbauer $\mathrm{K}$ et al (2003) Aberrant expression of peroxiredoxin subtypes in neurodegenerative disorders. Brain Res 967(1-2):152-160

98. Power JH et al (2008) Peroxiredoxin 6 in human brain: molecular forms, cellular distribution and association with Alzheimer's disease pathology. Acta Neuropathol 115(6):611-622

99. Melanson JE, Avery SL, Pinto DM (2006) High-coverage quantitative proteomics using amine-specific isotopic labeling. Proteomics 6(16):4466-4474

100. Pinho CM, Teixeira PF, Glaser E (2014) Mitochondrial import and degradation of amyloid-beta peptide. Biochim Biophys Acta 1837(7):1069-1074

101. Hansson Petersen CA et al (2008) The amyloid beta-peptide is imported into mitochondria via the TOM import machinery and localized to mitochondrial cristae. Proc Natl Acad Sci U S A 105(35):13145-13150

102. Silva PN et al (2014) Analysis of HSPA8 and HSPA9 mRNA expression and promoter methylation in the brain and blood of Alzheimer's disease patients. J Alzheimers Dis 38(1):165-170

103. Reed T et al (2008) Redox proteomic identification of 4-hydroxy2-nonenal-modified brain proteins in amnestic mild cognitive impairment: insight into the role of lipid peroxidation in the progression and pathogenesis of Alzheimer's disease. Neurobiol Dis 30(1):107-120

104. Guix FX et al (2009) Amyloid-dependent triosephosphate isomerase nitrotyrosination induces glycation and tau fibrillation. Brain 132(Pt 5):1335-1345

105. Park H et al (2012) Neuropathogenic role of adenylate kinase-1 in Abeta-mediated tau phosphorylation via AMPK and GSK3beta. Hum Mol Genet 21(12):2725-2737

106. Schonberger SJ et al (2001) Proteomic analysis of the brain in Alzheimer's disease: molecular phenotype of a complex disease process. Proteomics 1(12):1519-1528 
107. Choi J et al (2014) Potential roles of PINK1 for increased PGC1alpha-mediated mitochondrial fatty acid oxidation and their associations with Alzheimer disease and diabetes. Mitochondrion $18: 41-48$

108. Butterfield DA et al (2006) Redox proteomics identification of oxidatively modified brain proteins in inherited Alzheimer's disease: an initial assessment. J Alzheimers Dis 10(4):391-397

109. Singh NK et al (2014) Polymorphism in cytochrome P450 2D6, glutathione S-transferases Pi 1 genes, and organochlorine pesticides in Alzheimer disease: a case-control study in North Indian population. J Geriatr Psychiatry Neurol 27(2):119-127
110. Hamilton RL (2000) Lewy bodies in Alzheimer's disease: a neuropathological review of 145 cases using alpha-synuclein immunohistochemistry. Brain Pathol 10(3):378-384

111. Marui $\mathrm{W}$ et al (2000) Occurrence of human alpha-synuclein immunoreactive neurons with neurofibrillary tangle formation in the limbic areas of patients with Alzheimer's disease. J Neurol Sci 174(2):81-84

112. Larson ME et al (2012) Soluble alpha-synuclein is a novel modulator of Alzheimer's disease pathophysiology. J Neurosci 32(30): 10253-10266 